\title{
Wettability and osteoblast cell response modulation through UV laser processing of nylon 6,6
}

\author{
D.G. Waugh and J. Lawrence
}

School of Engineering, University of Lincoln, Brayford Pool, Lincoln, Lincolnshire, LN6 7TU, UK.

Corresponding Author:

D.G. Waugh

School of Engineering

University of Lincoln

Brayford Pool

Lincoln

Lincolnshire

LN6 7TS, UK

Email: Dwaugh@lincoln.ac.uk

Tel: +44 (0) 1522668891 


\section{0 - Abstract}

With an ageing population the demand for cheap, efficient implants is ever increasing. Laser surface treatment offers a unique means of varying biomimetic properties to determine generic parameters to predict cell responses. This paper details how a $\mathrm{KrF}$ excimer laser can be employed for both laser-induced patterning and whole area irradiative processing to modulate the wettability characteristics and osteoblast cell response following 24 hour and 4 day incubation. Through white light interferometry (WLI) it was found that the surface roughness had considerably increased by up to $1.5 \mu \mathrm{m}$ for the laser-induced patterned samples and remained somewhat constant at around $0.1 \mu \mathrm{m}$ for the whole area irradiative processed samples. A sessile drop device determined that the wettability characteristics differed between the surface treatments. For the patterned samples the contact angle, $\theta$, increased by up to $25^{\circ}$ which can be attributed to a mixed-state wetting regime. For the whole area irradiative processed samples $\theta$ decreased owed to an increase in polar component, $\gamma^{\mathrm{P}}$. For all samples $\theta$ was a decreasing function of the surface energy. The laser whole area irradiative processed samples gave rise to a distinct correlative trend between the cell response, $\theta$ and $\gamma^{\mathrm{P}}$. However, no strong relationship was determined for the laser-induced patterned samples due to the mixed-state wetting regime. As a result, owed to the relationships and evidence of cell differentiation one can deduce that laser whole area irradiative processing is an attractive technology for employment within regenerative medicine to meet the demands of an ageing population.

Keywords: Excimer laser, nylon 6,6, wettability, osteoblast cells, bioactivity, regenerative medicine.

\section{0 - Introduction}

It has been realized worldwide within the scientific community and various industries that lasers offer major advantages over alternative techniques for materials processing [1-4]. Some of the main advantages of using a laser for materials processing are:

- Relative cleanliness.

- Accurate processing.

o Allows much control over the Heat Affected Zone (HAZ) due to the ability of relative precise control over the thermal profile and thermal penetration/absorption. 
- Precise placement of the beam onto the target material allowing user specified areas of the target material to be processed.

- Post-processing techniques required are usually minimal.

- Non-contact processing.

- Automation (repeatability) of the various processing techniques using a laser is relatively easy to implement.

With a large number of different lasers now commercially available it is possible for one to deduce that almost all materials can be processed using a laser due to the wide range of laser parameters that can be utilized. With the many benefits of using lasers for materials processing it has been found that the interest in laser-induced surface treatment has grown, especially within the biomedical industry. This is due to the fact that lasers offer the user a highly selective, rapid technique to induce surface modification in both organic and inorganic materials [5].

In order to modify the surface properties of polymers for use in biological environments and enhance the cell response by improving upon the adhesion characteristics, a vast number of techniques and methods have been developed. These techniques range from surface topography modification [6-8] to surface chemistry modification [9-11] and have given rise to the increased interest in using polymers as biomaterials [12-19]. Nylon 6,6, the strongest and most abrasive resistant unreinforced nylon, has been used for such biological applications as sutures, tracheal tubes and gastrointestinal segments [20]. With regards to orthopedic applications it can be seen that nylon is not commonly employed due to the hygroscopic nature having a large affect on the mechanical properties over long periods of time [21]. Having said that, the use of nylon 6,6 within this work gives high value experimentally insofar as to ascertain generic factors for polymeric materials which could be used to predict the osteoblast cell response. Also, by modifying the surface of polymeric materials it may be possible to identify other biological applications as this may enhance the osteoblast cell response and biocompatibile properties. On account of nylon 6,6 being a relatively inexpensive polymer when compared to other polymer types, by identifying other applications for this material the biological industry would benefit by being able to implement cheaper, more economic bio-implant materials.

With numerous advances in medicine it has been seen that the population is ageing both within the U.K. and within other major countries around the world. On account of people living longer, a number of institutions have developed a focus on bioengineering to meet the ever growing demands on medical facilities [22]. Furthermore, it is possible for one to realize that with an ageing population there is an ever increasing demand for biological implants. As a result, these 
needs of the ageing population need to be met more economically and efficiently so that costs and the need for unnecessary surgery are considerably reduced. Therefore, it is imperative for the biomedical industry to devise a way to manufacture cheap implants which can be used in confidence to ensure a dramatic reduction in failure rates. This can be met by the laser surface treatment of polymeric materials to enhance their biomimetic properties.

On account of the many benefits offered by laser materials processing to life sciences this paper is a contribution to the endeavour of enhancing polymer surface properties to determine generic parameters which give rise to the level of biofunctionality. That is, this work undertakes an approach by which the laser modified surface parameters, wettability characteristics and osteoblast cell response are discussed in order to ascertain the variables which link the factors together as shown in Figure 1.

\section{0 - Experimental Technique}

\section{1 - Nylon 6,6 Material}

The nylon $6,6\left(\mathrm{~T}_{\mathrm{m}}: 255^{\circ}, \rho: 1.3 \mathrm{gcm}^{-3}\right)$ was sourced in $100 \mathrm{~mm}^{2}$ sheets with a thickness of $5 \mathrm{~mm}$ (Goodfellow Cambridge, Ltd). To obtain a conveniently sized sample for experimentation the asreceived nylon sheet was cut into $20 \mathrm{~mm}$ diameter discs using a $1 \mathrm{~kW}$ continuous wave (cw) $\mathrm{CO}_{2}$ laser (Everlase S48; Coherent, Ltd). No discernible heat affected zone (HAZ) was observed under optical microscopic examination.

\section{2 - KrF Excimer Laser-Induced Patterning}

For the patterned experiments the repetition rate of the KrF excimer laser (LPX 200i; Lambda Physik, Inc.) was kept constant at $25 \mathrm{~Hz}$, with a number of 10 pulses per site and used Aerotech $\mathrm{CNC}$ programming to induce the required pattern. A constant laser energy of $80 \pm 7 \mathrm{~mJ}$ was used with the attenuator set to $0.3(30 \%)$ giving a measured energy at the target sample of $23.67 \pm 2.5 \mathrm{~mJ}$, resulting in a fluence of $858 \pm 91 \mathrm{~mJ} / \mathrm{cm}^{2}$. In order to induce the intended pattern a projection imaging system was implemented with a focusing lens of x10 demagnification. The patterns induced using this technique were $50 \mu \mathrm{m}$ trench (ET50), $100 \mu \mathrm{m}$ trench (ET100), $50 \mu \mathrm{m}$ hatch (EH50) and $100 \mu \mathrm{m}$ (EH100). Two non-contact masks were used for both dimensioned patterns which included a brass mask with six $1 \mathrm{~mm}$ diameter holes spaced by $2 \mathrm{~mm}$, centre to centre, for the $100 \mu \mathrm{m}$ dimensions and a SS316 foil (Laser Micromachining Ltd., UK) with five $0.5 \mathrm{~mm}$ diameter holes spaced by $1.5 \mathrm{~mm}$, 'centre to centre', for the $50 \mu \mathrm{m}$ dimensions. To keep the constant 10 pulses per site it should also be noted here that scanning velocities of $0.125 \mathrm{mms}^{-1}$ and $0.25 \mathrm{mms}^{-1}$ were used for the $50 \mu \mathrm{m}$ and $100 \mu \mathrm{m}$ dimensioned patterns, respectively. 
No processing gases were used throughout the experimentation and all laser processing was carried out in an enclosure in which the ambient gas was air. Also, for all laser processing no homogenizer was implemented meaning that the raw beam was used which would have given rise to energy spikes pulse to pulse, having some possible affect on the incident laser fluence and laser material processing.

\section{3 -KrF Excimer Laser Whole Area Irradiative Processing}

For the whole area processing with the KrF excimer laser (LPX 200i; Lambda Physik, Inc.) the raw $23 \times 12 \mathrm{~mm}^{2}$ beam was used to irradiate a large section of each sample at a time. In order to hold the sample normal to the beam a bracket on the optical train was used. For the large area processing experiments 6 samples where studied; these being 100 pulses at $100 \mathrm{~mJ}$ (EWA100), 100 pulses at $150 \mathrm{~mJ}$ (EWA150), 100 pulses at $200 \mathrm{~mJ}$ (EWA200), 100 pulses at $250 \mathrm{~mJ}$ (EWA250), 500 pulses at $250 \mathrm{~mJ}$ (EWA250_500) and 1000 pulses at $250 \mathrm{~mJ}$ (EWA250_1000). This gave fluences of $36 \pm 3,54 \pm 5,72 \pm 8$ and $91 \pm 10 \mathrm{~mJ} / \mathrm{cm}^{2}$, respectively for the different energies used. Throughout the whole area excimer experiments the repetition rate was kept constant at $25 \mathrm{~Hz}$ and Aerotech $\mathrm{CNC}$ programming ensured that the correct number of pulses was applied to each sample.

\section{4 - Topography, Wettability Characteristics and Surface Chemistry Analysis}

After laser irradiation the nylon 6,6 samples were analysed using a number of techniques. The surface profiles were determined using a white light interferometer (WLI) (NewView 500; Zygo, Ltd) with MetroPro and TalyMap Gold Software. The WLI was set-up using a $\times 10$ Mirau lens with a zoom of $\times 0.5$ and working distance of $7.6 \mathrm{~mm}$. This system also allowed $\mathrm{Sa}$ and $\mathrm{Ra}$ roughness parameters to be determined for each sample. Where Ra can be defined as the arithmetic average of the absolute values along a single specified direction and Sa the arithmetic average of the absolute values over the whole of the laser surface treated area.

In accordance with the procedure detailed by Rance [23] the samples were ultrasonically cleaned in isoproponal (Fisher Scientific Ltd.) for 3 minutes at room temperature before using a sessile drop device to determine various wettability characteristics. This was to allow for a relatively clean surface prior to any contact angle, $\theta$, measurements being taken. To ensure that the sample surfaces were dry a specimen dryer (Metaserv, Ltd.) was employed to blow ambient air across the samples. A sessile drop device (OCA20; Dataphysics Instruments, $\mathrm{GmbH}$ ) was used with relevant software (SCA20; Dataphysics Intrsuments, $\mathrm{GmbH}$ ) to allow the recent advancing and receding $\theta$ 
for triply distilled water and the recent advancing angle for diiodomethane to be determined for each sample. By starting with a droplet with a volume of $8 \mu 1$ then the advancing $\theta$ were achieved by adding and removing $0.5 \mu \mathrm{l}$, respectively, for each measurement. Thereafter the advancing $\theta$ for the two liquids were used by the software to draw an OWRK plot to determine the surface energy of the samples. For the two reference liquids the SCA20 software used the Strom et al technique (triply distilled water - SFT(total:72.80), SFT(D:21.80), SFT(P:51.00); diiodomethane SFT(total:50.80), SFT(D:50.80), SFT(P:0.00)) to calculate the surface energy of the material. It should be noted here that ten $\theta$, using two droplets in each instance, were recorded to achieve a mean $\theta$ for each liquid and surface.

All samples were analysed using x-ray photoelectron spectroscopy (XPS). This allowed any surface modifications in terms of surface oxygen content due to the laser irradiation to be revealed. Further details on XPS measurements of surface oxygen content have been stated previously [24].

\section{5 - In Vitro Experimentation}

Prior to any biological testing being carried out the samples were autoclaved (D-Series Bench-Top Autoclave; Systec, $\mathrm{GmbH}$ ) to ensure that all samples were sterilized. For all biological work undertaken, unless stated, a biological safety cabinet (BSC) (Microflow Class II ABS Cabinet; BioQuell UK, Ltd) was used to create a safe working environment and to provide a clean, sterile environment to manipulate the cells used.

Normal human osteoblast cells (Clonetics CC-2538; Lonza, Inc.) were initially cultured in a T75 (75 ml) flask by suspending the cells in $19 \mathrm{ml}$ culture medium comprising of $90 \%$ eagle minimum essential medium (Sigma-Aldrich, Ltd., UK) and 10\% foetal bovine serum (FBS) (Sigma-Aldrich Ltd., UK). The flask was then placed in an incubator and left for $24 \mathrm{hrs}$. After $24 \mathrm{hrs}$ the cells were assessed and the spent media was aspirated before dispensing $15 \mathrm{ml}$ of fresh media and returning the flask to the incubator for three days.

The period of three days allowed the cells to become confluent in the flask providing enough cells for seeding onto the samples. The cells were detached from the flask using $5 \mathrm{ml}$ Trypsin-EDTA (Sigma-Aldrich Ltd., UK) whilst placed in the incubator for seven minutes. Once all cells had become detached $10 \mathrm{ml}$ culture medium was added to neutralize the Trypsin. In order to aspirate the supernatant the cell culture was centrifuged (U-320R; Boeco, GmbH) for five minutes at $200 \mathrm{~g}$. To ensure the cells were ready for seeding they were resuspended in $10 \mathrm{ml}$ of culture medium and dispensed between the samples in the 6-well plates. This equated to $0.55 \mathrm{ml}\left(2 \times 10^{4} \mathrm{cells} / \mathrm{ml}\right)$ for each sample. The well plates were then placed in the incubator for a set time. One plate was 
removed after 24 hrs and two other plates after four days. A well plate after 24 hrs and 4 days was prepared for the SEM as will be discussed later and the other plate, removed after 4 days, was prepared for counting using an improved neubauer hemacytometer (Fisher Scientific Ltd., UK) by mixing $10 \mu \mathrm{l}$ of each cell suspension with $10 \mu \mathrm{l}$ of trypan-blue (Sigma-Aldrich Ltd., UK). In order to harvest the cells for counting the cells were detached from the samples using $2 \mathrm{ml}$ TrypsinEDTA (Sigma-Aldrich Ltd., UK) whilst placed in the incubator for seven minutes. Once all cells had become detached $4 \mathrm{ml}$ culture medium was added to neutralize the Trypsin. In order to aspirate the supernatant the cell culture was centrifuged (U-320R; Boeco, $\mathrm{GmbH}$ ) for five minutes at $200 \mathrm{~g}$. To ensure the cells were ready for counting they were resuspended in $2 \mathrm{ml}$ of culture medium and $2 \mathrm{ml}$ of the trypan-blue was added.

\section{6 - Scanning Electron Microscopy and Cell Cover Density of In Vitro Samples}

In order to view the attached cells using SEM it was necessary to undertake a procedure to produce a sample that was dehydrated ready for Au coating. The samples were initially rinsed with phosphate-buffered saline (PBS) (Sigma-Aldrich, UK) to remove any unattached cells and then adherent cells were fixed using 1.2\% glutaraldehyde in water (Sigma-Aldrich, UK) at room temperature for one hour within the BSC. After an hour the glutaraldehyde solution was removed and the fixed cells were washed with PBS prior to carrying out a graded series of ethanol/distilled water mixtures of 50/50,80/20,90/10,95/5, 98/2 and 100/0. Each sample was left in these mixtures for $10 \mathrm{~min}$ to ensure dehydration. Once this procedure was carried out, the samples were mounted and sputter coated with Au so that SEM micrographs could be obtained. In order to produce the best images possible each image was manipulated in terms of brightness, contrast and gamma by using ImagePro Version 5.0.0.39 for Windows XP/Professional software (Media Cybernetics Inc., USA).

In addition to the cell count described in Section 3.5, the cell cover density was determined following both $24 \mathrm{hrs}$ and 4 day incubation. This was done by analysing the cell coverage on each sample using SEM and optical micrographs with the ImagePro software. The optical micrographs were obtained using an up-right optical microscope (Flash 200 Smartscope; OGP, Ltd) with magnifications varying between $\times 20$ and $\times 100$. 


\section{0 - Results and Discussion}

\section{1 - Topography}

\subsection{1 - KrF Excimer Laser-Induced Patterning}

It can be seen in Figure 2 that the topography of the nylon 6,6 had been modified significantly through excimer laser patterning when compared to the as-received sample (see Figure 2(a)). For the $50 \mu \mathrm{m}$ dimensioned patterns (see Figure 2(b) and Figure 2(d)) trench depths of around $1.5 \mu \mathrm{m}$ was obtained from the employed laser processing parameters. These constant laser processing parameters also gave rise to trench depths of roughly 4 to $5 \mu \mathrm{m}$ for the $100 \mu \mathrm{m}$ dimensioned patterned samples (see Figure 2(c) and Figure 2(e)). What is more, on account of the accuracy and precision of the excimer laser system implemented, the trenches produced in the nylon 6,6 materials which can be seen in Figures 2(b) to (e) were highly periodic. This periodicity was also confirmed upon obtaining the profile extractions as shown in Figures 2(b) to (e).

Table 1 gives the surface roughness values for each of the $\mathrm{KrF}$ excimer laser-induced patterned samples and shows that the surface roughness had dramatically increased for the excimer laser patterned samples. For instance, the largest increases were seen with the $100 \mu \mathrm{m}$ dimensioned patterns which had an Sa of approximately $1.5 \mu \mathrm{m}$. This can be seen to be on account of the fact that the $100 \mu \mathrm{m}$ dimensioned patterned samples gave rise to deeper trenches in comparison to the $50 \mu \mathrm{m}$ dimensioned samples.

\subsection{2 - KrF Excimer Laser Whole Area Irradiative Processing}

Through WLI it was found that the KrF excimer laser whole area irradiative processed samples (see Figure 3) appeared to have a similar topography to that of the as-received sample (see Figure 2(a)). This can be attributed to the fact that the whole sample was irradiated meaning that any ablation taking place would remove a somewhat uniform layer from the surface of the nylon 6,6. On the other hand, especially for the samples with low incident fluences, it may be possible that the material did not ablate on account of the threshold fluence not being achieved.

With regards to surface roughness the whole area irradiated samples had roughnesses equivalent to that of the as-received sample (AR) which had an Sa of $0.126 \mu \mathrm{m}$ and an Ra of $0.029 \mu \mathrm{m}$ (see Table 1). This can be accounted for by the observation through the WLI which showed a negligible effect on the surface topography for these samples. This further confirms that the fluences implemented for these samples was not sufficient to elicit an ablative response from the nylon 6,6 samples. Having said that, it may still have been possible for surface chemistry changes to occur due to oxidation. This is on account of the fact that directly after the irradiation of the samples using the $\mathrm{KrF}$ excimer laser, the 
samples were warm to the touch, with the warmest sample being WA250_1000 which had 1000 pulses and the highest fluence of $91 \mathrm{mJcm}^{-2}$.

\section{2 - Wettability and Surface Oxygen Content}

\subsection{1 - KrF Excimer Laser-Induced Patterning}

Table 1 gives a summary of the surface parameters and wettability characteristics for each of the samples studied. On account of the $\mathrm{KrF}$ excimer laser-induced patterning of the nylon 6,6 samples $\theta$ increased by up to $24^{\circ}$ in comparison to the as-received sample (AR) which had a $\theta$ of $56.4 \pm 1.2^{\circ}$. This did not appear to corroborate with current theory as an increase in surface roughness for a hydrophilic material should bring about a reduction in $\theta$ [5]. This increase in $\theta$ arising from the excimer patterned samples can be accounted for by the reduction in apparent polar component, $\gamma^{\mathrm{P}}$, and apparent total surface free energy, $\gamma^{\mathrm{T}}$, which is modified by the liquids equilibrium state. That is, the wetting regime had changed on account of the surface topography with the likelihood being that the transition was to a mixed-state wetting regime in which both Wenzel and Cassie-Baxter regimes formed along the liquid-surface interface [25-31]. It should also be noted here that Table 1 confirms that as a result of the $\mathrm{KrF}$ excimer laser-material oxidation of the surface was observed, allowing the surface oxygen content to increase by at most $1.6 \%$ at. The largest increase in surface oxygen content was found to be from the hatch patterned samples (EH50 and EH100) owed to the fact that more material was ablated inducing more surface oxidation.

From Figure 4 it can be seen that $\theta$ was an inverse function of $\gamma^{\mathrm{P}}$ (see Figure 4(a)) and $\gamma^{\mathrm{T}}$ (see Figure (b) which does agree with current theory for a hydrophilic material such as nylon 6,6 . This suggests that even though there is a likely-hood of a mixed-state wetting regime is arising on the $\mathrm{KrF}$ excimer laser patterned samples $\gamma^{\mathrm{P}}$ and $\gamma^{\mathrm{T}}$ still play a distinct role in terms of the wettability of the nylon 6,6 . It is also possible to ascertain from Figure 4(b) that similar values of $\gamma^{\mathrm{T}}$ give rise to equivalent values of $\theta$. That is, with a $\gamma^{\mathrm{T}}$ of approximately $30 \mathrm{mJm}^{-2}$, a $\theta$ of between 75 and $80^{\circ}$ could be expected.

Figure 5 shows the correlation arising between $\theta$ and the surface roughness parameters Ra and Sa. For the $\mathrm{KrF}$ excimer laser-induced patterned samples it can be seen that $\theta$ is an increasing function of both $\mathrm{Ra}$ and Sa with the exception of the last data point which was for sample EH100 which had an Ra of $1.032 \mu \mathrm{m}$, an Sa of $1.530 \mu \mathrm{m}$ and a resulting $\theta$ of $73 \pm 3.7^{\circ}$. This could suggest that an increase in the surface roughness gives rise to an increase in $\theta$ until a certain point at which $\theta$ remains constant or begins to decrease by which time would then start to correspond with current theory insofar as an increase in surface roughness gives rise to a more hydrophilic response [5]. Furthermore, this could suggest that over the different rough periodic surfaces a transition in wetting regime could have taken place and would explain the decrease in $\theta$ for the roughest sample (sample EH100). 


\subsection{2 - KrF Excimer Laser Whole Area Irradiative Processing}

From Table 1 it can be seen that the $\mathrm{KrF}$ excimer laser whole area irradiated samples gave rise to a decrease in $\theta$ of up to $20^{\circ}$. The largest decrease in $\theta$ was observed for samples WA250_500 and WA250_1000 which had the largest fluence of $91 \mathrm{mJm}^{-2}$ and more pulses compared to the other samples. The reduction observed in $\theta$ can be attributed to the increase in $\gamma^{\mathrm{P}}$ and $\gamma^{\mathrm{T}}$. In terms of surface oxygen content it was seen that there was an increase of up to $5 \%$ at. which could have also given rise to the reduction in $\theta$. Another factor which can be taken from Table 1 is that the surface roughness variation was negligible compared to the as-received sample (AR) which had an Ra of $0.029 \mu \mathrm{m}$ and Sa of $0.12 \mu \mathrm{m}$. Therefore, it stands to reason that $\gamma^{\mathrm{P}}$ and $\gamma^{\mathrm{T}}$ or the surface oxygen content in this instance had to be the most dominant in determining the wettability of nylon 6,6 following $\mathrm{KrF}$ excimer laser whole area irradiative processing.

Figure 4 shows that $\theta$ over all $\mathrm{KrF}$ excimer laser whole area processed samples was an inverse function of $\gamma^{\mathrm{P}}$ (see Figure 4(a)) and $\gamma^{\mathrm{T}}$ (see Figure 4(b) with very good correlation. What is more it can be seen from Figure 4 that those samples which had equivalent $\gamma^{\mathrm{P}}$ or $\gamma^{\mathrm{T}}$ values gave rise to similar observed $\theta$. For instance, for $\gamma^{\mathrm{P}}$ values of around 22 and $25 \mathrm{mJm}^{-2}, \theta$ was approximately 51 and $48^{\circ}$ (see Figure 4(a)). Also, from Figure 4(b) it can be seen that samples with similar $\gamma^{\mathrm{T}}$ of around $51 \mathrm{mJm}^{-2}$ gave rise to $\theta$ in the region of $50^{\circ}$.

Figure 5 shows a reasonable inverse correlation between the surface roughness and $\theta$ for all $\mathrm{KrF}$ excimer laser whole area irradiative processed samples. However, on account of the relatively small variations in $\mathrm{Ra}$ and $\mathrm{Sa}$ for these samples, a conclusive relationship between surface roughness and $\theta$ could not be determined.

\subsection{3 - Comparison Between KrF Excimer Laser-Induced Patterning and KrF Excimer Laser Whole Area Irradiative Processing}

Table 1 allows one to identify that there was some significant differences between the as-received (AR), $\mathrm{KrF}$ excimer laser-induced patterned and $\mathrm{KrF}$ excimer laser whole area processed nylon 6,6 samples in terms of surface parameters and wettability characteristics. It was observed that for the $\mathrm{KrF}$ laser-induced patterned samples $\theta$ increased even though there was a significant increase in surface roughness. This increase in $\theta$ can be attributed to the reduction in $\gamma^{\mathrm{P}}$ and $\gamma^{\mathrm{T}}$ and the likelihood of a transition in wetting regime. On the other hand, it was found that on account of an increase in $\gamma^{\mathrm{P}}$ and $\gamma^{\mathrm{T}}, \theta$ decreased for the $\mathrm{KrF}$ excimer laser whole area irradiative processed nylon 6,6 samples. It was observed that for all $\mathrm{KrF}$ excimer laser processed samples the surface oxygen content increased by up to $5 \%$ at. when compared to the as-received sample (AR). This increase in surface oxygen 
content indicates that this may have given rise to the observed reduction in $\theta$ for the laser whole area processed samples. Still, this does not seem to be the case as a reduction in $\theta$ was not observed for the $\mathrm{KrF}$ excimer laser-induced patterned samples. This suggests that a significant variation in surface topography of the nylon 6,6 may bring about the change in wettability regime; whereas when there is no significant variation in topography it is possible that a variation in wettability is brought about by other parameters such as $\gamma^{\mathrm{P}}$ and $\gamma^{\mathrm{T}}$. In addition, even though there was a change in wetting regime for the $\mathrm{KrF}$ excimer laser-induced patterned samples to account for the increase of Sa and Ra, it was still found that $\theta$ remained strongly linked to variations in $\gamma^{\mathrm{P}}$ and $\gamma^{\mathrm{T}}$.

In terms of collating the $\gamma^{\mathrm{P}}$ and $\gamma^{\mathrm{T}}$ results for the entire $\mathrm{KrF}$ excimer laser processed samples and the effects thereof on $\theta$, Figure 4 shows that there was a strong inverse function correlation between $\theta$ and the surface energy parameters regardless of the processing technique used. This indicates that $\gamma^{\mathrm{P}}$ and $\gamma^{\mathrm{T}}$ could be the main driving parameters determining the wettability of the nylon 6,6 samples in this instance. As a result it may be possible to use these parameters as indicators of how nylon 6,6 will wet due to similar values of $\gamma^{\mathrm{P}}$ and $\gamma^{\mathrm{T}}$ giving rise to equivalent $\theta$, as discussed in Section 4.2.1 and Section 4.2.2.

\section{3 - Osteoblast Cells: 24 hours Incubation}

\subsection{1 - KrF Excimer Laser-Induced Patterning}

After $24 \mathrm{hrs}$ incubation time for the osteoblast cell seeded samples it can be seen from the SEM micrographs shown in Figure 6 that the cells had begun to adhere and proliferate across each of the $\mathrm{KrF}$ excimer laser-induced patterned nylon 6,6 samples. Similar to the as-received sample (see Figure 6(a)) the $\mathrm{KrF}$ excimer laser-induced patterned samples gave rise to osteoblast cells with a bipolar cell morpohology. In addition to this, one major difference between the cell growth on the as-received sample (see Figure 6(a)) and the $\mathrm{KrF}$ excimer laser-induced patterned samples is that the excimer patterned nylon 6,6 samples gave rise to some form of directionality; that is, the cells appeared to be preferentially growing along the grooves formed by the excimer laser. This could have been induced by the surface roughness and surface oxygen content being higher (see Table 1) in the etched grooves allowing for preferential cell growth.

Figure 7 allows one to see that in terms of cell cover density, following $24 \mathrm{hrs}$ of incubation, the $\mathrm{KrF}$ excimer laser-induced patterned nylon 6,6 samples gave rise to a cell cover density equivalent to that observed with the as-received sample (AR). That is, all of the $\mathrm{KrF}$ excimer laser-induced patterned samples gave a cell cover density of around $20 \%$ suggesting that the nylon 6,6 surfaces had not given rise to a more enhanced osteoblast cell response following $\mathrm{KrF}$ excimer laser patterning. 


\subsection{2 - KrF Excimer Laser Whole Area Irradiative Processing}

Figure 8 shows the SEM micrographs for the $\mathrm{KrF}$ excimer laser whole area irradiative processed nylon 6,6 samples after $24 \mathrm{hrs}$ incubation. From this it can be seen that the $\mathrm{KrF}$ excimer whole area irradiative processed samples gave rise to variations in cell morphology in comparison to the asreceived sample (see Figure 6(a)) in that, the cells shown in Figure 8 appeared to be more clumped radial. This can be attributed to the fact that the combination of differing wettability characteristics and surface oxygen content is likely to have contributed to cell differentiation. As a result, one can deduce that by modulating cell differentiation through varying wettability characteristics and surface oxygen content there is a large potential for using laser surface treated polymeric materials within regenerative medicine.

It is apparent from Figure 7 that all of the $\mathrm{KrF}$ excimer laser whole area irradiative processed samples gave rise to larger cell cover densities when compared to the as-received sample (AR) with the exception of sample EWA250_500 and sample EWA250_1000. The largest cover density of 25\% was obtained with samples EWA100, EWA150, EWA250 and EWA250 which was 5\% more than what was observed for the as-received sample (AR). Sample EWA250_500 and sample EWA250_1000 gave rise to a reduction in osteoblast cell response (see Figure 7) and could be attributed to the samples becoming too hydrophilic (see Table 1) in which the modified nylon 6,6 surfaces were not sufficient to promote an enhanced osteoblast cell response. That is, materials that are too hydrophilic are well known for their cell-repellant properties and hinder the initial protein adsorption needed for a positive cell response $[18,32]$.

\subsection{3 - Wettability Characteristics and Surface Parameters}

By taking into account the effects of $\theta$ on the osteoblast cell response following 24 hrs incubation, it can be seen that the data plotted in Figure 7 suggested a possible threshold window for $\theta$ between 47 and $53^{\circ}$ which gave rise to an enhanced osteoblast cell response in terms of cell cover density. On the other hand, this also indicates that above or below this $\theta$ threshold window the osteoblast cell response would inherently be hindered slowing the cell proliferation and reducing the cell cover density. Also, for the $\mathrm{KrF}$ excimer laser-induced patterned samples which gave rise to the largest $\theta$ of approximately 70 to $80^{\circ}$ it can be seen from Figure 7 that the cell cover density reduced to around $18 \%$. This is highly significant when compared to the other samples with $\theta$ between 47 and $53^{\circ}$ because these samples gave rise to the largest cell cover densities of $25 \%$ or more allowing one to extrapolate that a $\theta$ threshold window is likely. 
The likelihood of a threshold window is further confirmed when accounting for $\gamma^{\mathrm{P}}$ and $\gamma^{\mathrm{T}}$. Such that Figure 7 shows there was a $\gamma^{\mathrm{P}}$ threshold window of 17 to $25 \mathrm{mJm}^{-2}$ and a window of 47 to $53 \mathrm{mJm}^{-2}$ for $\gamma^{\mathrm{T}}$ which gave rise to an enhanced osteoblast cell response in terms of cell cover density. It should also be noted here that the relationship between the cell cover density, $\theta$ and $\gamma^{\mathrm{P}}$ are mostly the inverse to one another and can be attributed to the relationship between $\gamma^{\mathrm{P}}$ and $\theta$. From this the inverse relationship for the two parameters with the cell cover density further attests to the relationship between $\theta$ and $\gamma^{\mathrm{P}}$.

It should noted here that Figure 7 also suggests that even though a threshold window could be possible, the KrF excimer laser-induced patterned nylon 6,6 samples did not conclusively follow the trend. This is due to those samples with $\gamma^{\mathrm{T}}$ of around $30 \mathrm{mJm}^{-2}$ giving rise to a variation of cell cover densities ranging between 16 and $21 \%$. This can be accounted for by the likelihood of a mixed-state wetting regime arising on these samples which would have had a large impact upon how the osteoblast cells reacted to the patterned nylon 6,6 surfaces.

In addition, Figure 7 allows one to see that the cell cover density for the $\mathrm{KrF}$ laser processed samples after $24 \mathrm{hrs}$ of incubation was a decreasing function of the surface oxygen content such that the lowest cell cover densities of around $17 \%$ were achieved when the surface oxygen content had increased up to $18 \%$ at. Having said that, it is well known that an increase in surface oxygen content should bring about an enhanced cell response [5]. An explanation for this observed phenomena can be attributed to a potential increase in surface toxicity whilst oxidation took place during the laser surface treatment. This is on account of the nylon 6,6 potentially becoming excessively toxic through degradation of the nylon 6,6 surface giving rise to toxic substances which would hinder cell growth. Even though these substances may be present it is likely that surface oxidation would have taken place and would explain the increase in surface oxygen content and reduction in cell count for the KrF excimer laser processed samples. This can be attributed to the fact that at the higher fluences further melting could cause the surface of the nylon 6,6 to become more toxic which would hinder cell growth compared to the other samples. That is, upon considerable degradation of the nylon 6,6 it is known that toxic substances such as $\mathrm{CO}$ and $\mathrm{HCN}$ can evolve [33]. These evolved toxic substances could have been present on the surface on account of the rapid heating and cooling, trapping these substances until they leached out into the cell media. This would have had a considerable deleterious effect on the osteoblast cell growth as it has been shown that $\mathrm{CO}$ and $\mathrm{HCN}$ affect cell growth and proliferation [34].

Following 24 hrs of incubation it has been observed that $\theta, \gamma^{\mathrm{P}}, \gamma^{\mathrm{T}}$ and indirectly the surface oxygen content all had an influence on modulating the osteoblast cell response to the laser surface treated samples. From the results obtained it was also found that there was no specific trend identified 
between the surface roughness and the osteoblast cell response following $24 \mathrm{hr}$ incubation. This allows one to see that the surface roughness parameters were not a dominant parameter in determining the osteoblast cell response. Also, on account of some erroneous results from the laser-induced patterned samples the laser whole area irradiative processed samples seemed to give rise to the highest potential for use in regenerative medicine. This is because of the likely mixed-state wetting regime arising on the laser-induced patterned samples having a large impact upon the osteoblast cell response.

\section{4 - Osteoblast Cells: 4 Days Incubation}

\subsection{1 - KrF Laser-Induced Patterning}

With four days of incubation elapsed, Figure 9 shows that the cell growth was at an advanced stage for the $\mathrm{KrF}$ excimer laser-induced patterned nylon 6,6 samples compared to what was observed following 24 hrs incubation time (see Figure 6). From Figure 9 it can be seen that the cell morphology for the as-received sample was radial and coral-like which differed from the $\mathrm{KrF}$ excimer laserinduced patterned samples which gave a more clumped like morphology. It can also be identified using Figure 9 that there appeared to be more directionality for the $\mathrm{KrF}$ excimer laser-induced patterned samples compared to the as-received sample. As discussed following 24 hrs incubation, this could potentially be due to the grooves being rougher giving rise to more preferential cell growth in these areas.

It can be seen from Figure 10 that the $\mathrm{KrF}$ excimer laser-induced patterning of the nylon 6,6 samples gave rise to cover densities of just under $100 \%$ which was equivalent to that observed for the asreceived sample (AR). To confirm if the bioactivity had changed for the $\mathrm{KrF}$ excimer laser-induced patterned samples compared to the as-received sample (AR) after four days of incubation cell count was also taken into account. Figure 11 allows one to realize that the cell count was also equivalent to that of the as-received sample which was around 40,000 cells $/ \mathrm{ml}$. By knowing this, it was possible to see that the $\mathrm{KrF}$ excimer laser-induced patterned nylon 6,6 samples did not give rise to an enhanced osteoblast cell response when compared to the as-received sample (AR). Having said that, the $\mathrm{KrF}$ excimer laser-induced patterned nylon 6,6 samples did not hinder cell response either and as such can be seen to give an equivalent response to that seen with the as-received sample. In fact, the only difference which could be ascertained between the as-received sample and the $\mathrm{KrF}$ excimer laserinduced patterned samples was that of the cell morphology which can be attributed to surface parameter variations on account of the laser-material interaction. 


\subsection{2 - KrF Excimer Laser Whole Area Irradiative Processing}

Figure 12 shows the SEM micrographs for the $\mathrm{KrF}$ excimer laser whole area irradiative processed nylon 6,6 samples following four days incubation. As one can see the osteoblast cells were at an advanced stage of cell growth following 4 days of incubation. Furthermore, it can be seen that the morphologies appear to have varied somewhat. Sample EWA100 (see Figure 12(a)) gave rise to a more clumped like whereas the other samples (see Figure 12(b) to Figure 12(f)) gave rise to a more radial cell morphology. This further suggests that the variation in surface properties as a result of the laser treatment had a significant impact upon cell signalling and can be seen as an attractive means for potential use within regenerative medicine.

Figure 10 shows that the cell cover density for all of the $\mathrm{KrF}$ excimer laser whole area irradiative processed samples tended towards $100 \%$ after 4 days of incubation. However, it can be said that the lowest cell cover density was determined for sample EWA250_1000 which had a cell cover density of around $83 \%$. This is significant as it suggests that a considerably more hydrophilic surface such as sample EWA250_1000 gave rise to a less enhanced osteoblast cell response as discussed in Section 4.3.2.

To further confirm the effects of the $\mathrm{KrF}$ excimer laser whole area irradiative processing on the osteoblast cell response after four days a cell count was undertaken. Figure 11 shows that most of the $\mathrm{KrF}$ excimer laser whole area irradiative processed samples gave rise to a larger cell count of around 47,000 cells $/ \mathrm{ml}$ when compared to the as-received sample (AR) which had a cell count of just less than 40,000 cells $/ \mathrm{ml}$. By comparing the $\mathrm{KrF}$ excimer laser whole area irradiative processed samples alone it was found that upon an increasing fluence and incident pulse numbers, the cell count reduced considerably to the point where sample EWA250_500 and sample EWA250_1000 had a cell count around 33,000 cells $/ \mathrm{ml}$ which was less than that of the as-received sample (AR). This can allow one to see that these samples hindered the osteoblast cell response in comparison to the as-received sample (AR).

\subsection{3 - Wettability Characteristics and Surface Parameters}

Figure 11 shows that for the $\mathrm{KrF}$ excimer laser-induced patterned samples there did not appear to be any correlative relationship between the cell count and $\theta$. This can be further accounted for by the transition in wetting regime which is likely to have had effect on the osteoblast cell response. On the contrary, it can be seen from Figure 11 that the $\mathrm{KrF}$ excimer laser whole area irradiative processed samples could to some extent have had a correlation between the cell count and $\theta$. Since, the cell count appears to have reduced on account of a drop in $\theta$. 
It can also be seen from Figure 11 that there did not appear to be any correlation between $\gamma^{\mathrm{P}}$ and the cell count for the $\mathrm{KrF}$ excimer laser-induced patterned nylon 6,6 samples. In general, for the $\mathrm{KrF}$ excimer laser whole area irradiative processed samples Figure 11 shows that there could have been a slight correlative trend in that the cell count reduced on account of an increase in $\gamma^{\mathrm{P}}$. In addition to this, the data presented in Figure 11 to some extent shows an inverse relationship between $\theta$ and $\gamma^{\mathrm{P}}$ and as such supports the relationship between $\theta$ and $\gamma^{\mathrm{P}}$ identified in Section 4.2.

Figure 11 allows one to see that upon a significant reduction in $\gamma^{\mathrm{T}}$ for the $\mathrm{KrF}$ excimer laser-induced patterned samples the cell count increased slightly by up to 5,000 cells $/ \mathrm{ml}$ compared to the asreceived sample (AR). Similarly, for the KrF excimer laser whole area irradiative processed samples it was found that the cell count decreased dramatically on account of an increase in $\gamma^{\mathrm{T}}$. Furthermore, from Figure 11 one can see that for all of the $\mathrm{KrF}$ excimer laser processed nylon 6,6 samples the cell count had a strong correlation with surface oxygen content in that an increase in surface oxygen content brought about a reduction in the cell count, coinciding with what has been observed previously in Section 4.3.3. However, as stated in Section 4.3.3 this does not necessarily mean that an increase in the surface oxygen content hinders cell response but could be used as an indirect indicator of how a KrF excimer laser processed nylon 6,6 will perform when in contact with osteoblast cells.

Similar to the observations following $24 \mathrm{hrs}$ incubation, there were no observations as to any correlation between the surface roughness parameters $\mathrm{Ra}$ and $\mathrm{Sa}$ and the osteoblast cell response. This indicates that the surface roughness following laser surface treatment was not a dominating parameter governing the biomimetic nature of the laser surface modified nylon 6,6. In Section 4.3.3 it was seen that there could potentially be an operating threshold window for $\theta, \gamma^{\mathrm{P}}$ and $\gamma^{\mathrm{T}}$ in order for $\mathrm{KrF}$ excimer laser processed nylon 6,6 to give an enhanced osteoblast cell response. However, after 4 days incubation these trends have not been identified and suggest that the two different KrF excimer laser processing techniques do not correlate to the same trend when accounting for the osteoblast cell response. Having said that, it may be the case that the surface parameters and wettability characteristics played a more significant role in the preliminary stages of cell growth, explaining the reduction in correlative trends observed after four days of incubation. Even so, trends to some extent have been observed for the laser whole area irradiative processed samples over both the $24 \mathrm{hrs}$ and 4 day incubation period. As a result of this, one can say that the laser whole area irradiative processing technique holds more promise in the prediction of cell response and has more potential for use within regenerative medicine. 


\section{0 - Conclusions}

It has been further demonstrated that UV lasers offer an efficient and convenient means of surface modifying materials. It has been shown that a $\mathrm{KrF}$ excimer laser can be used for two different types of laser surface treatment: surface patterning and whole area irradiative processing. These different types of $\mathrm{KrF}$ excimer laser surface treatment have been seen to give rise to different topographies and wettability modifications on the nylon 6,6 samples. For the laser-induced patterned samples $\theta$ was found to have increased by up to $24^{\circ}$ when compared to the as-received sample even though Ra and Sa had increased; whereas the $\mathrm{KrF}$ excimer laser whole area processed samples gave $\theta$ to either be equivalent to the as-received sample or have a $\theta$ less by up to $20^{\circ}$. The increase in $\theta$ for the $\mathrm{KrF}$ excimer laser-induced patterned samples can be explained by the likely presence of a mixed-state wetting regime. Having said that, even though a change in wetting regime is likely it has still been observed that $\gamma^{\mathrm{P}}$ and $\gamma^{\mathrm{T}}$ still play a big role in the wettability of nylon 6,6 such that $\theta$ was a decreasing function of $\gamma^{\mathrm{P}}$ and $\gamma^{\mathrm{T}}$.

The $\mathrm{KrF}$ excimer laser surface treatment employed throughout this study had a significant impact on cell response in terms of cell differentiation, cell cover density and cell count. After 24 hrs incubation it was seen that the osteoblast cells had begun to adhere and proliferate across the surface of each of the nylon 6,6 samples with the majority of laser-modified samples giving rise to larger cover densities. Leading on, following 4 days of incubation it was found that all samples had given rise to an advanced stage of cell growth giving cell cover densities of around $100 \%$. However, it was seen that the cell count had increased for most of the laser processed samples indicating a more bioactive surface.

Those samples irradiated with low incident fluences and pulse numbers gave rise to the largest enhancements in bioactivity. However, on account of the erratic results obtained for the laser-induced patterned samples due to the likely influence from the mixed-state wetting regime, less correlative trends between the different parameters were identified. This allows one to see that the laser whole area irradiative processing technique is a more attractive method for modulating and predicting osteoblast cell response. Overall, it has been determined that the laser-induced modifications have given rise to modulated osteoblast cell response in terms of cell proliferation and differentiation. Therefore, on account of the differing surface parameters giving rise to the modulation of cell responses one can deduce that laser surface treatment holds a large potential to be widely employed within regenerative medicine. 


\section{0 - Acknowledgements}

The authors would like to thank their collaborators: Directed Light Inc., East Midlands NHS Innovation Hub, Nobel Biocare and Photomachining Inc. for all of their much appreciated support. The authors would also like to thank Chemical Engineering, Loughborough University for use of their biological laboratory. This study was financially supported by the EPSRC (EP/E046851/1).

\section{0 - References}

1. W.M. Steen, Laser Material Processing: Third Ed, Springer-Verlag, London, UK, 2005.

2. J.C. Ion, Laser Processing of Engineering Materials: Principles, Procedure and Industrial Application, Elsevier Butterworth-Heinemann, Oxford, UK, 2005.

3. S.E. Nielsen, Laser material processing of polymers, Polym. Test. 3 (1983) 303-310.

4. M. Von Allmen, A. Blatter, Laser-Beam Interactions With Materials: Physical Principles and Applications: Second Ed., Springer-Verlag, New York, USA, 1995.

5. L. Hao, J. Lawrence, Laser Surface Treatment of Bio-Implant Materials, John Wiley \& Sons Inc., New Jersey, USA, 2005.

6. K.S. Tiaw, M.H. Hong, S.H. Teoh, Precision laser micro-processing of polymers, J. Alloys Compd. 449 (2008) 228-231.

7. E. Sarantopoulou, Z. Kollia, A.C. Cefalas, A.M. Douvas, M. Chatzichristidi, P. Argitis, S. Kobe, Polymer self-assembled nano-structures and surface relief gratings induced with laser at $157 \mathrm{~nm}$, Appl. Surf. Sci. 253 (2007) 7884-7889.

8. K. Callewaert, Y. Martele, L. Breban, K. Naessens, P. Vandaele, R.Baets, G. Geuskens, E. Schacht, Excimer laser induced patterning of polymeric surfaces, Appl. Surf. Sci. 208-209 (2003) 218-225.

9. E.S.A. Hegazy, H.A. Abdel-Rehim, H. Kamal, K.A. Kandeel, Advances in radiation grafting, Nucl. Inst. Meth. Phys. Res. B 185 (2001) 235-240.

10. J. Zhang, J. Khang, P. Hu, Q. Meng, Surface modification of poly(propylene carboante) by oxygen ion implantation, Appl. Surf. Sci. 253 (2007) 5436-5441.

11. S. Dadbin, Surface modification of LDPE film by $\mathrm{CO}_{2}$ pulsed laser irradiation, Euro. Polym. J. 38 (2002) 2489-2495.

12. C. Mao, W. Zhao, C. Zhu, A. Zhu, J. Shen, S. Lin, In vitro studies of platelet adhesion on UV radiation-treated nylon surface, Carbohydr. Polym. 59 (2005) 19-25.

13. F. Yu, F. Mucklich, P. Li, H. Shen, S. Mathur, C.M. Lehr, U. Bakowsky, In vitro cell response to a polymer surface micropatterned by laser interference lithography, Biomacromol. 6 (2005) 11601167. 
14. W. Pfleging, M. Bruns, A. Welle, S. Wilson, Laser-assisted modification of polystyrene surfaces for cell culture applications, Appl. Surf. Sci. 253 (2007) 9177-9184.

15. H. Mirzadeh, M. Dadsetan, Influence of laser surface modifying of polyethylene terephthalate on fibroblast cell adhesion, Radiat. Phys. Chem. 67 (2003) 381-385.

16. H. Mirzadeh, A.A. Katbab, R.P. Burford, $\mathrm{CO}_{2}$-laser graft copolymerization of HEMA and NVP onto ethylene-propylene rubber (EPR) as biomaterial-(III), Radiat. Phys. Chem. 46 (1995) 859-862.

17. Q.F. Wei, W.D. Gao, D.Y. Hou, X.Q. Wang, Surface modification of polymer nanofibres by plasma treatment, Appl. Surf. Sci. 245 (2005) 16-20.

18. M.S. Kim, G. Khang, H.B. Lee, Gradient polymer surfaces for biomedical applications, Prog. Polym. Sci. 33 (2008) 138-164.

19. F.Z. Cui, Z.S. Luo, Biomaterials modification by ion-beam processing, Surf. Coat. Technol. 112 (1999) 278-285.

20. S.R. Paital, N.B. Dahotre, Calcium phosphate coatings for bio-implant applications: Materials, performance factors and methodologies, Mater. Sci. Eng. R 66 (2009) 1-70.

21. J.J. Rajesh, J. Bijwe, B. Venkataraman, U.S. Tewari, Effect of water absorption on erosive wear behaviour of polyamides, J. Mater. Sci. 37 (2002) 5107-5113.

22. K. MacGregor, The ageing population: U.K. focus for biomedical engineering - policy briefing. The Royal Academy of Engineering 2010.

23. D.G. Rance, Chapter 6 - thermodynamics of wetting: From its molecular basis to technological application, in: D.M. Brewis (ed.), Surface Analysis and Pretreatment of Plastics and Metals, Applied Science Publishers, Essex, UK, 1982. p.121.

24. D.G. Waugh, J. Lawrence, The enhancement of biomimetic apatite coatings by means of $\mathrm{KrF}$ excimer laser surface treatment of nylon 6,6, Lasers Eng. 21 (2011) 95-114.

25. X. Wu, L. Zheng, D. Wu, Fabrication of superhydrophobic surfaces from microstructured ZnObased surfaces via a wet-chemical route, Langmuir 21 (2005) 2665-2667.

26. S.M. Lee, T.H. Kwon, Effects of intrinsic hydrophobicity on wettability of polymer replicas of a superhydrophobic lotus leaf, J. Micromech. Microeng. 17 (2007) 687-692.

27. X. Chen, T. Lu, The apparent state of droplets on a rough surface, Sci. China Ser. G.Phys. Mech. Astron. 52 (2009) 233-238.

28. Y.T.Cheng, D.E. Rodak, C.A. Wong, C.A. Hayden, Effects of Micro- and Nano-Structures on the Self-Cleaning Behaviour of Lotus Leaves, Nanotechnol. 17 (2006) 1359-1362.

29. D.G. Waugh, J. Lawrence, D.J. Morgan, C.L. Thomas, Interaction of $\mathrm{CO}_{2}$ laser-modified nylon with osteoblast cells in relation to wettability, Mater. Sci. Eng. C 29 (2009) 2514-2524.

30. D.G. Waugh, J. Lawrence, C.D. Walton, R.B. Zakaria, On the effects of using $\mathrm{CO}_{2}$ and $\mathrm{F}_{2}$ lasers to modify the wettability of a polymeric biomaterial, J. Opt. Laser Technol. 42 (2010) 347-356. 
31. D.G. Waugh, J. Lawrence, On the use of $\mathrm{CO} 2$ laser induced patterns to modify the wettability of poly(methyl methamecrylate) (PMMA). Opt. Lasers Eng. 48 (2010) 707-715.

32. M.C. Lensen, V.A. Schulte, J. Salber, M. Diez, F. Menges, M. Moller, Cellular response to novel, micropatterned biomaterials. Pure Appl. Chem. 80 (2008) 2479-2487.

33. Sigma-Aldrich. Nylon 6,6 Material Safety Data Sheet - Version 3.0. 2008.

34. S.D. Cook, J.P. Ryaby, J.R.N. McCabe, J.J. Frey, J.D. Heckman, T.K. Kristiansen, Acceleration of tibia and distal radius fracture healing in patients who smoke. Clin. Ortho. Rel. Res. 337 (1997) 198-207. 


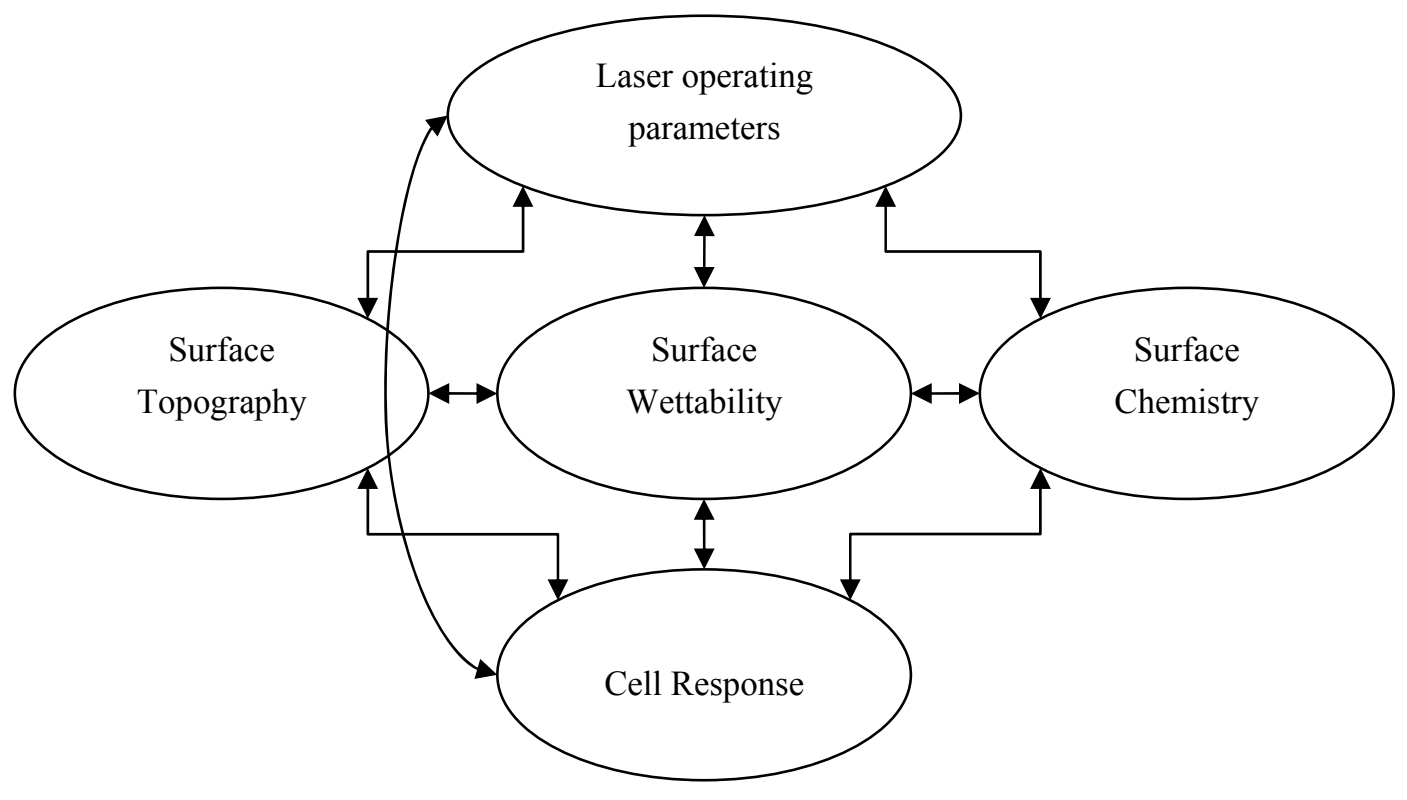

Figure 1 - Schematic diagram showing the deduced links between the factors arising throughout the research. 

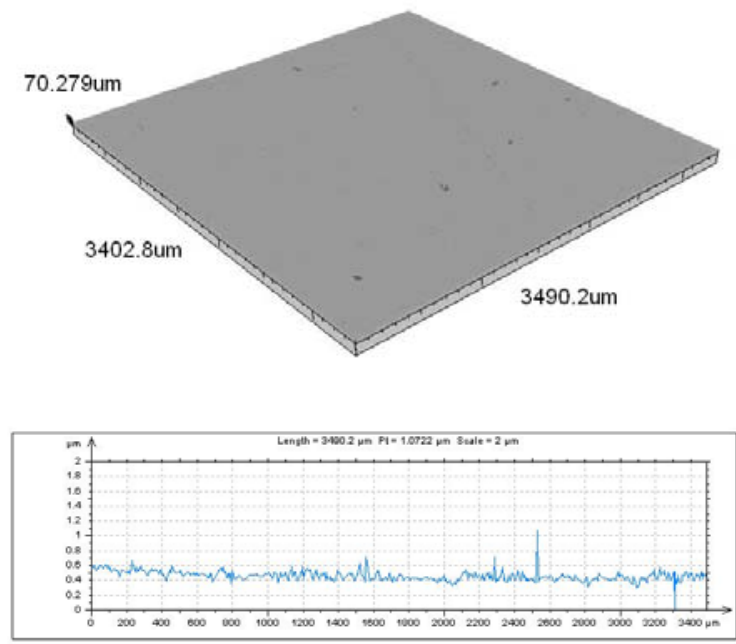

(a)
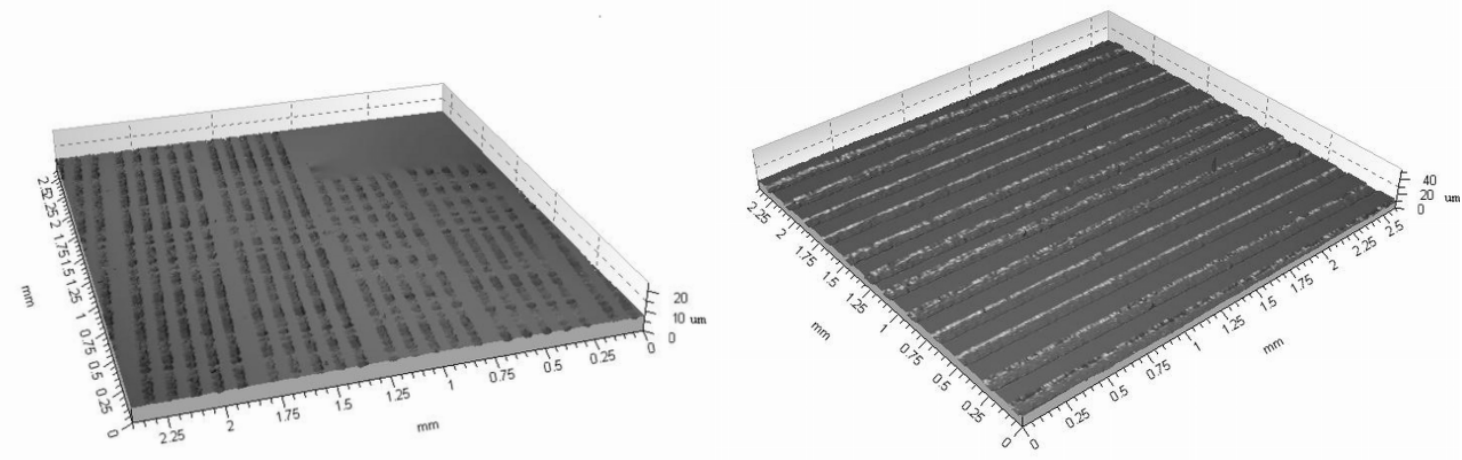

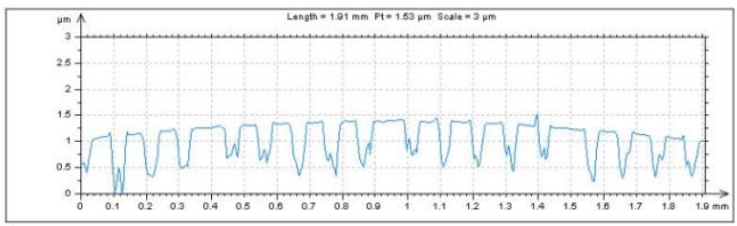

(b)
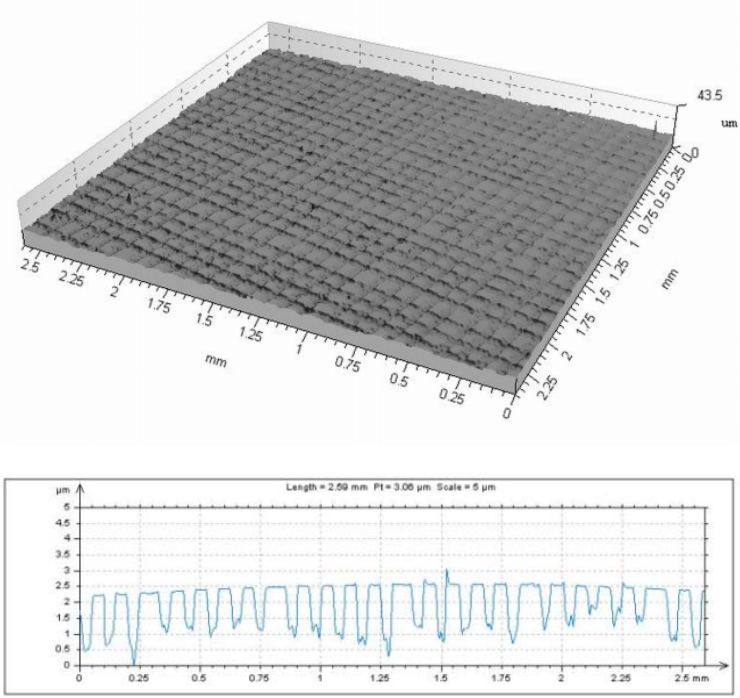

(d)

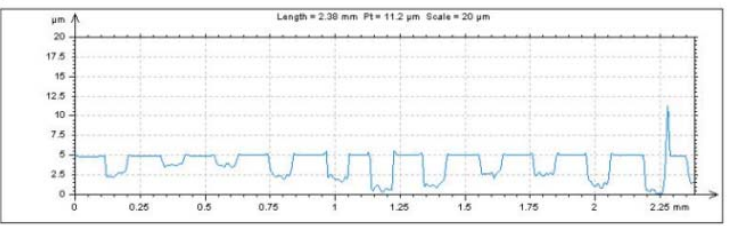

(c)
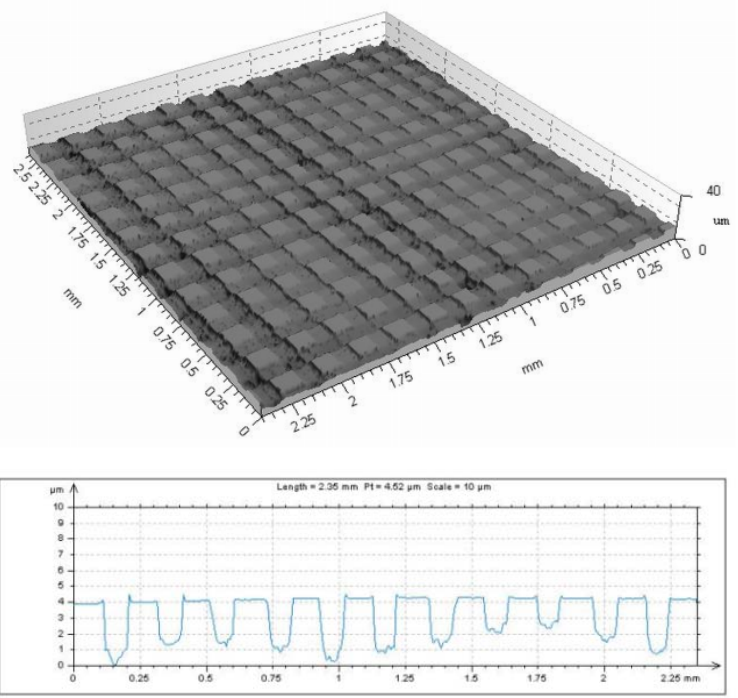

(e)

Figure 2 -Continuous axonometric 3-D images and profile extractions for the (a) as-received samples and for the KrF excimer laser patterned samples (b) ET50, (c) CT100, (d) EH50 and (e) H10. 

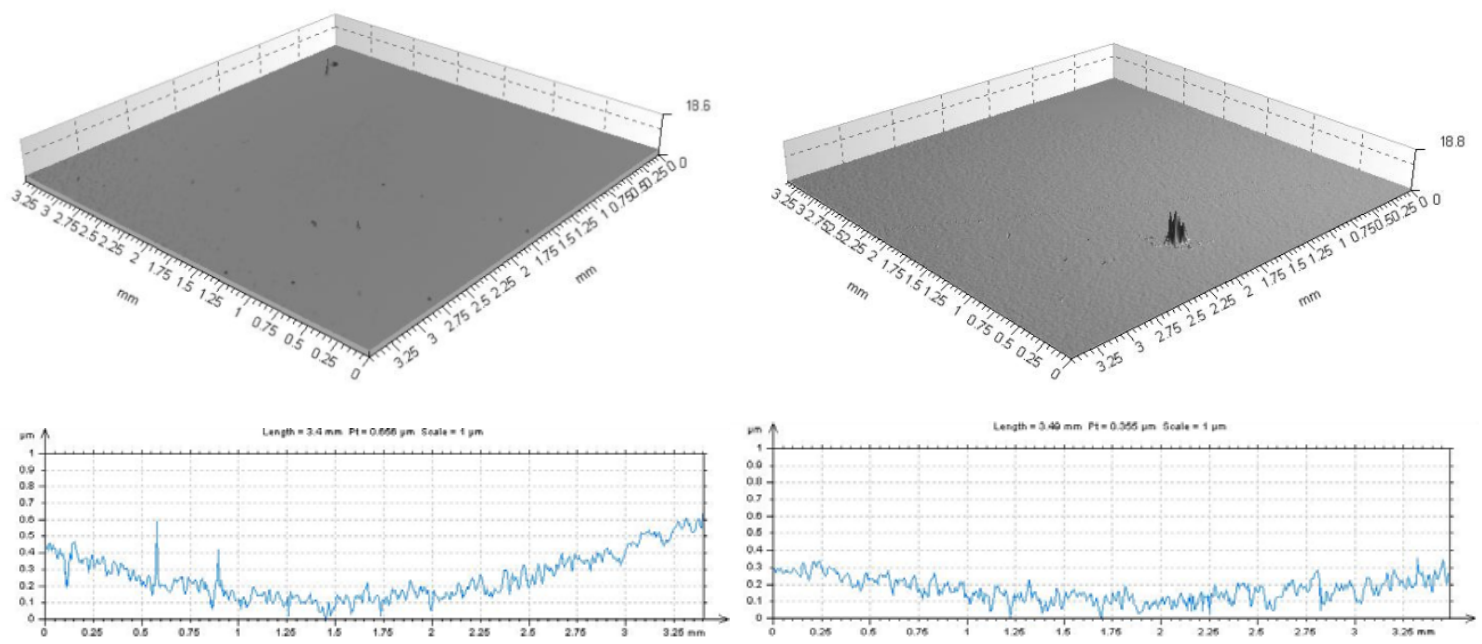

(a)

(b)
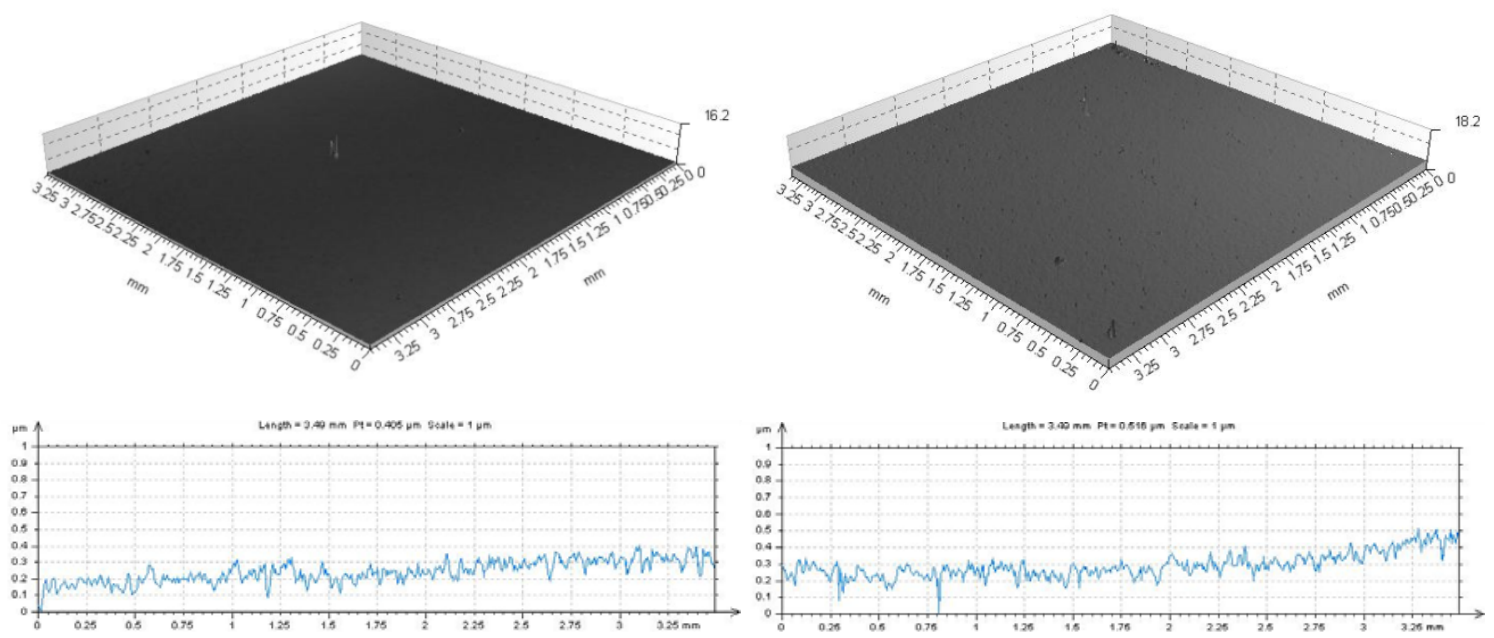

(c)

(d)
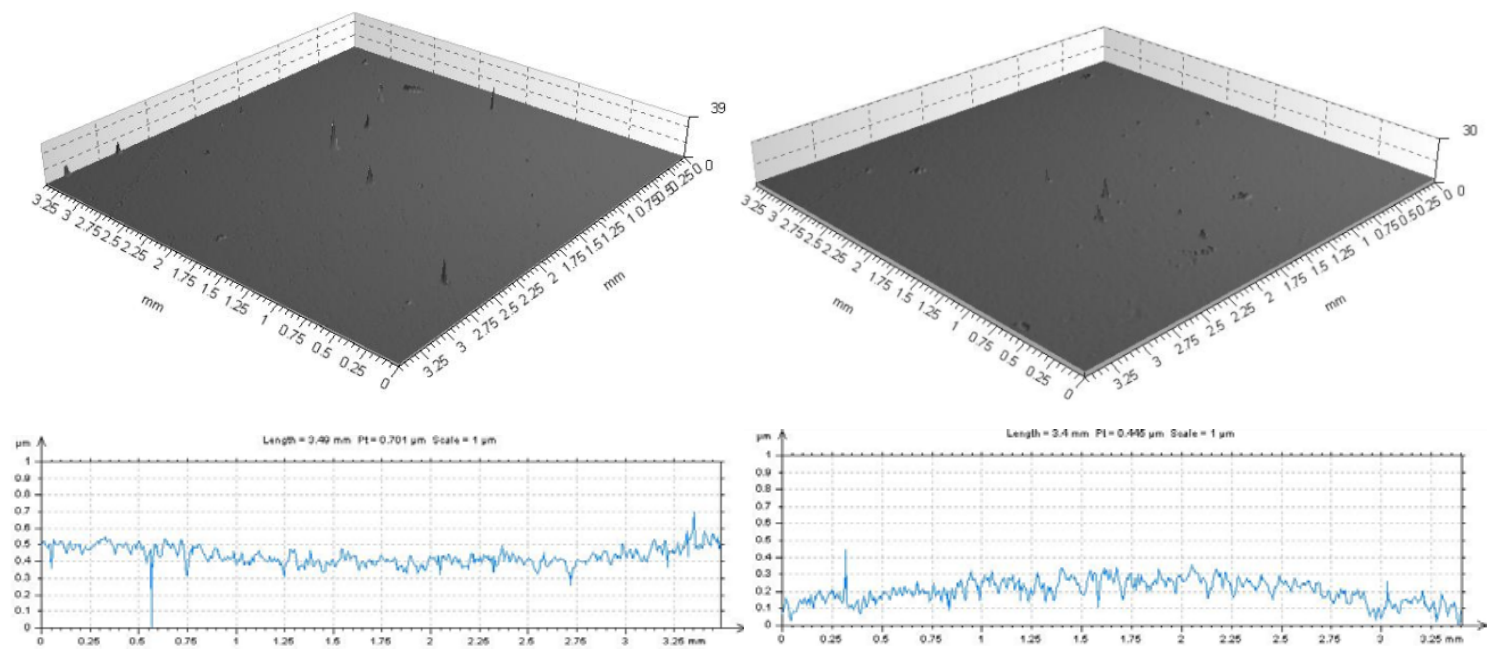

(e)

(f)

Figure 3 - Continuous axonometric 3-D images and profile extractions for (a) EWA100, (b) EWA150, (c) EWA200, (d) EWA250, (e) EWA250_500 and (f) EWA250_1000. 


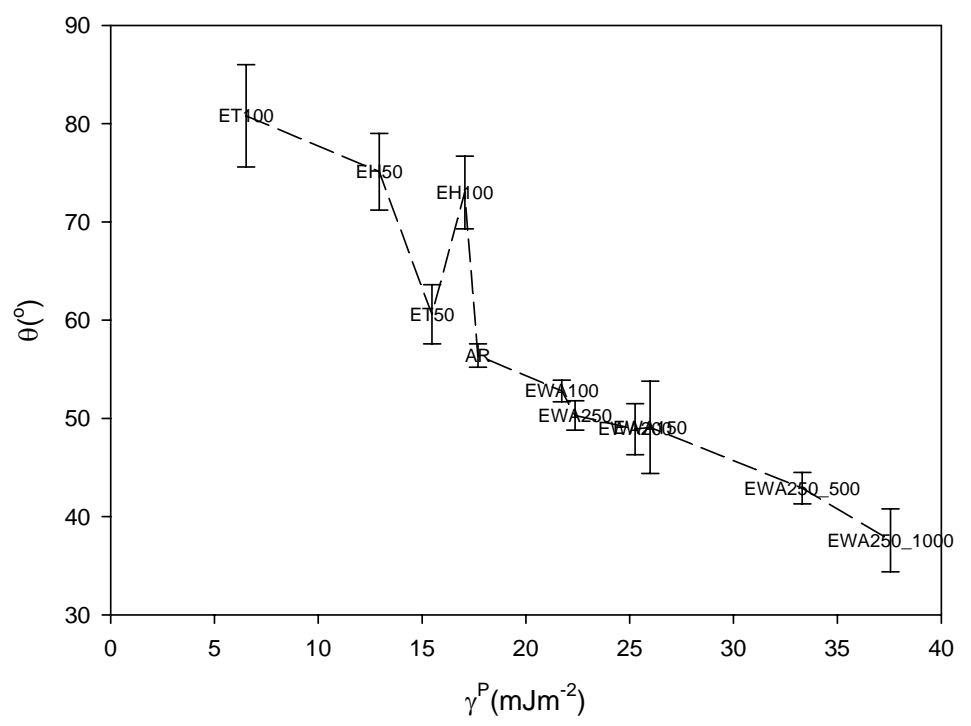

(a)

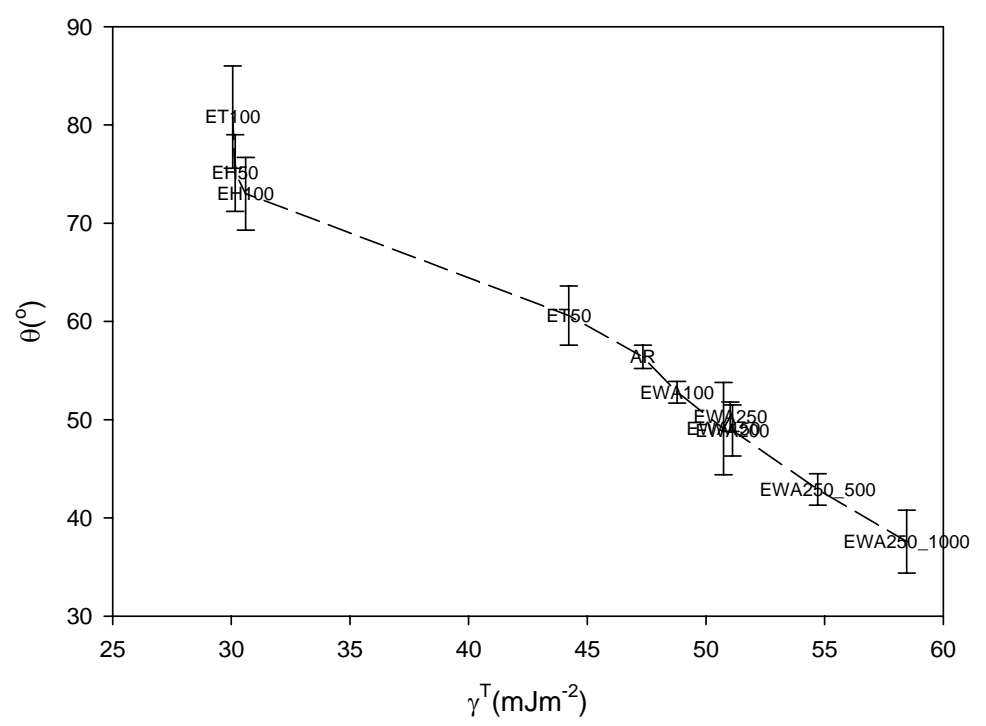

(b)

Figure 4-Graphs showing the correlation between $\theta$ and (a) $\gamma^{P}$ and (b) $\gamma^{T}$. 


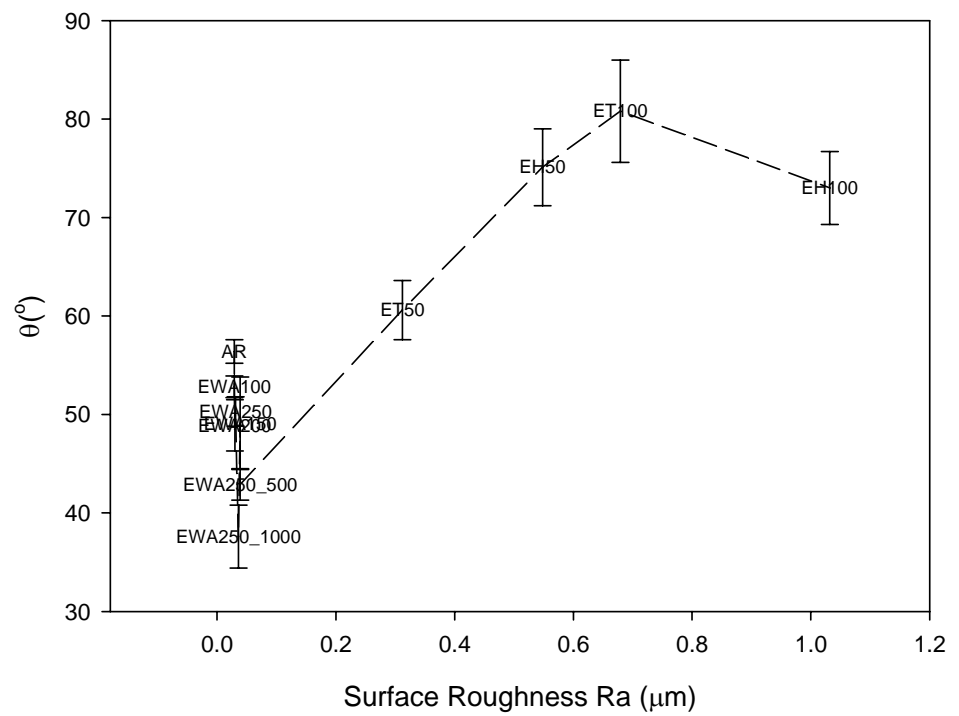

(a)

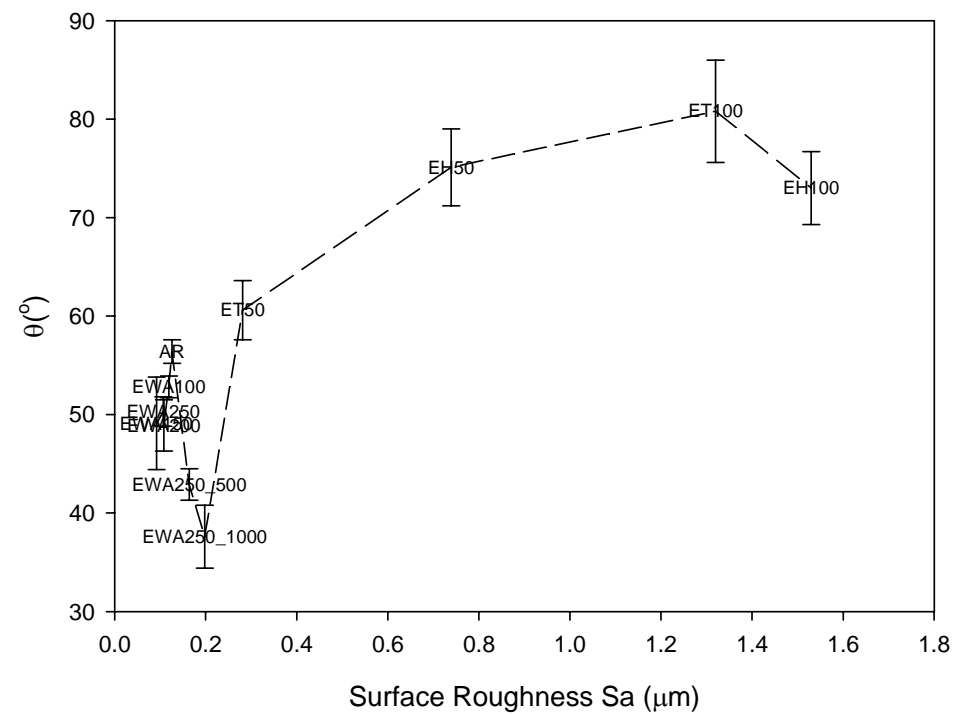

(b)

Figure 5-Graphs showing the correlation between $\theta$ and (a) Ra and (b) Sa. 


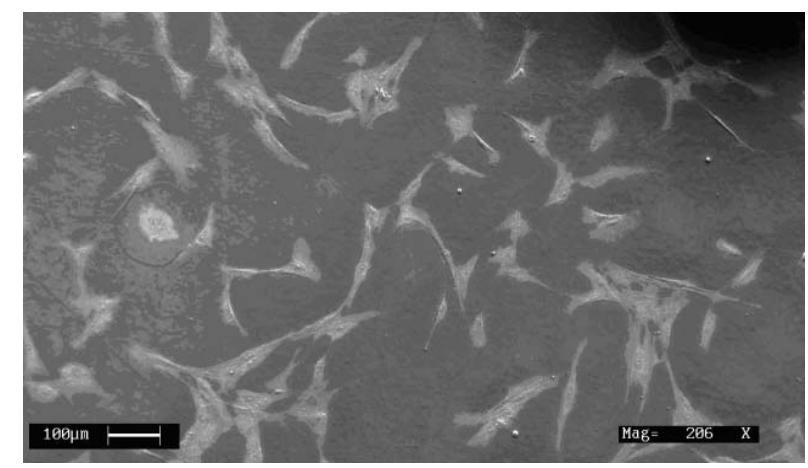

(a)

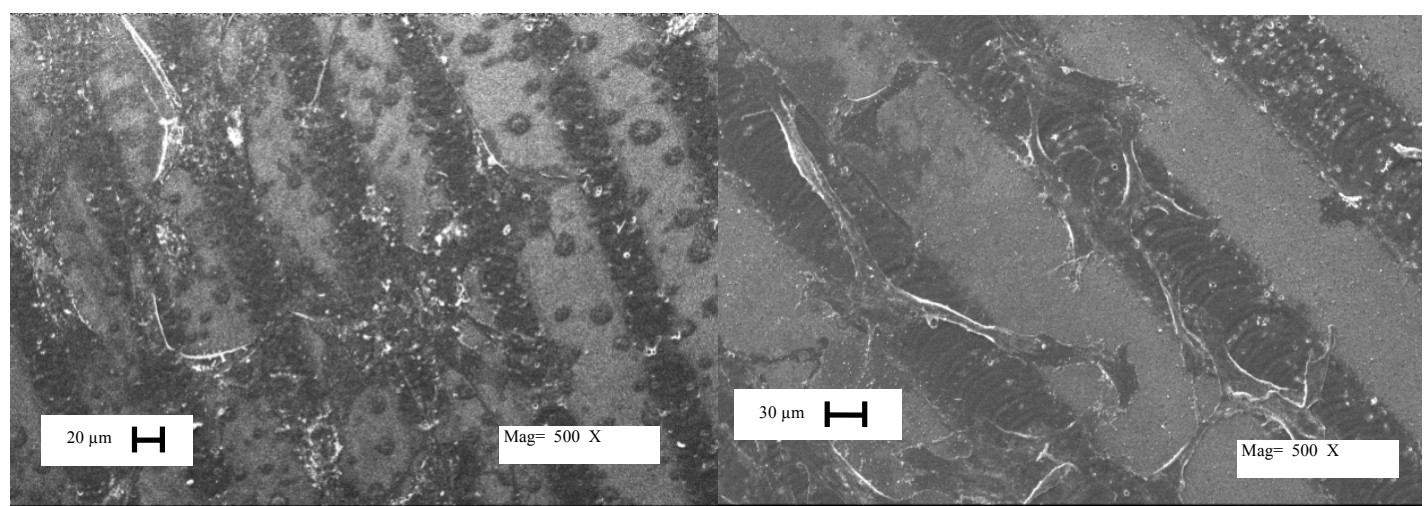

(b)

(c)

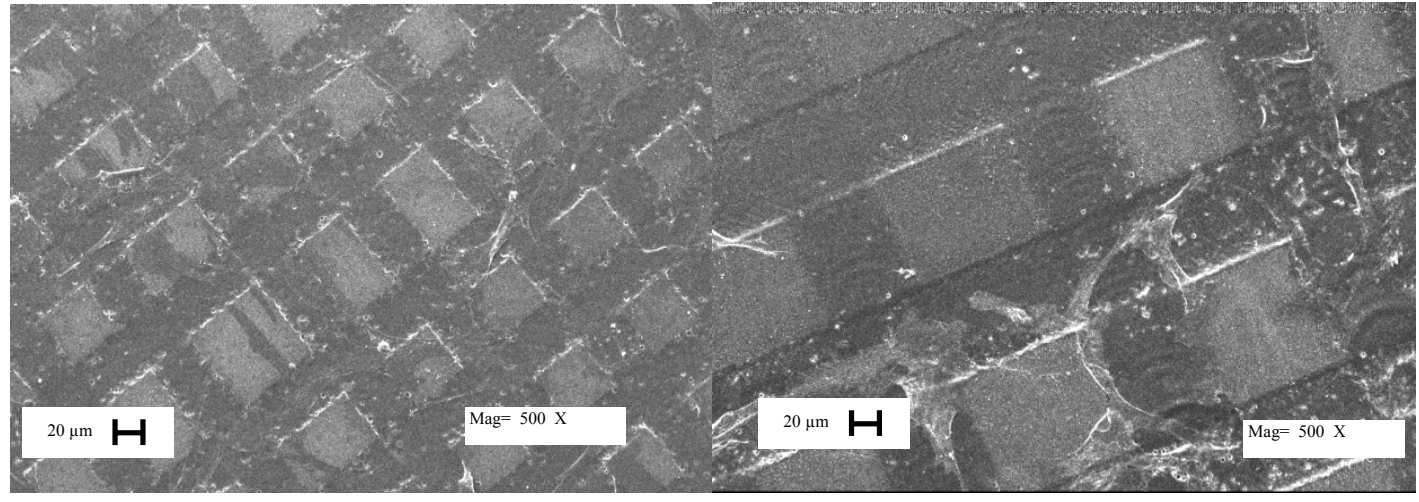

(d)

(e)

Figure 6-SEM micrographs of the (a) as-received sample and the KrF excimer laser-induced patterned samples (b) ET50, (c) ET100, (d) EH50 and (e) EH100 after 24 hrs incubation. 


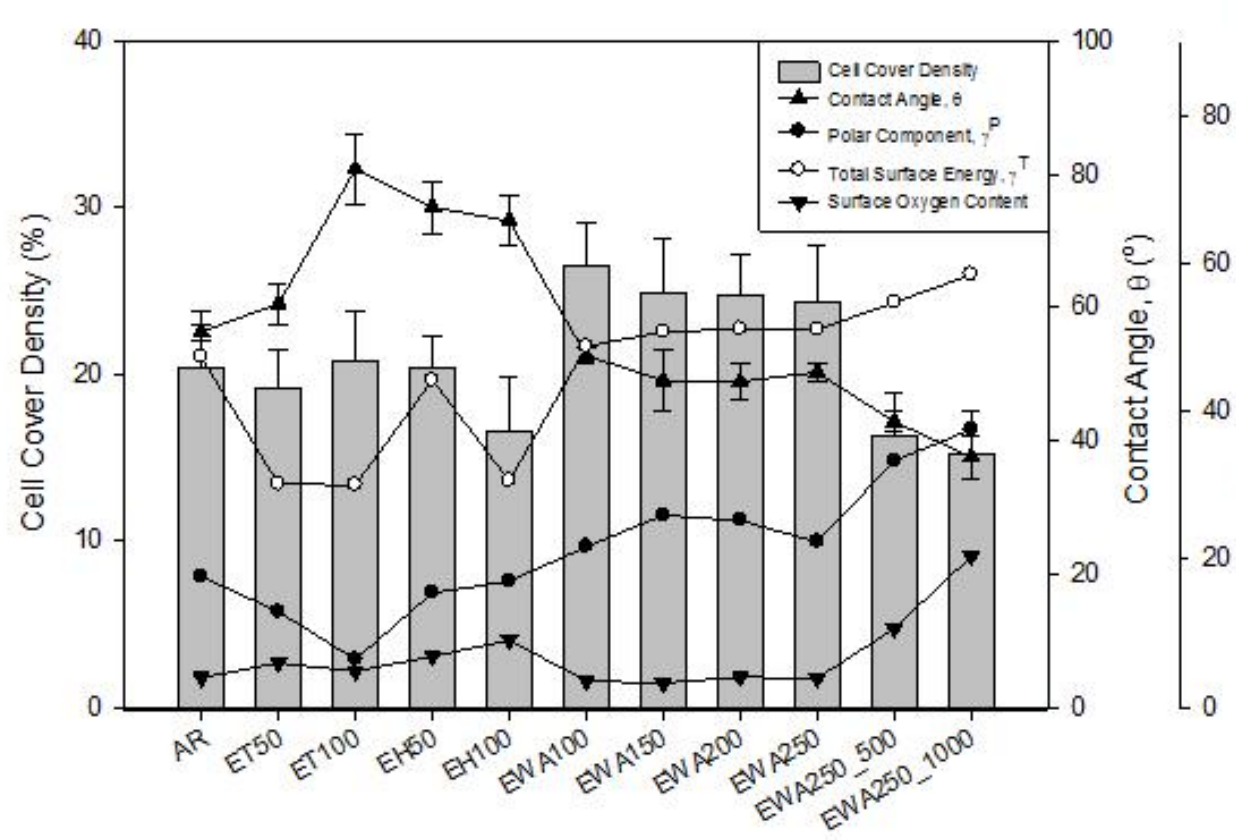

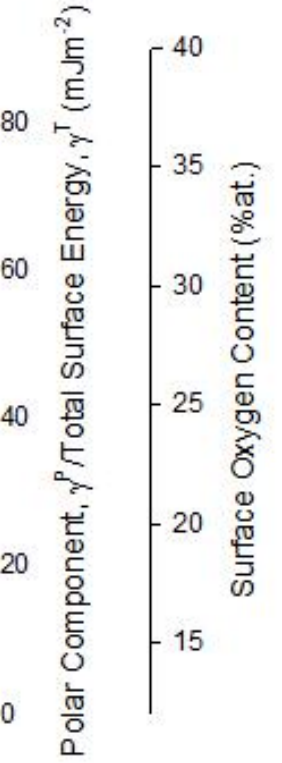

Sample 1.D.

Figure 7 - Histogram showing the cell cover density in relation to $\theta, \gamma^{P}, \gamma^{T}$ and surface oxygen content for all KrF excimer laser processed samples following 24 hrs incubation. 


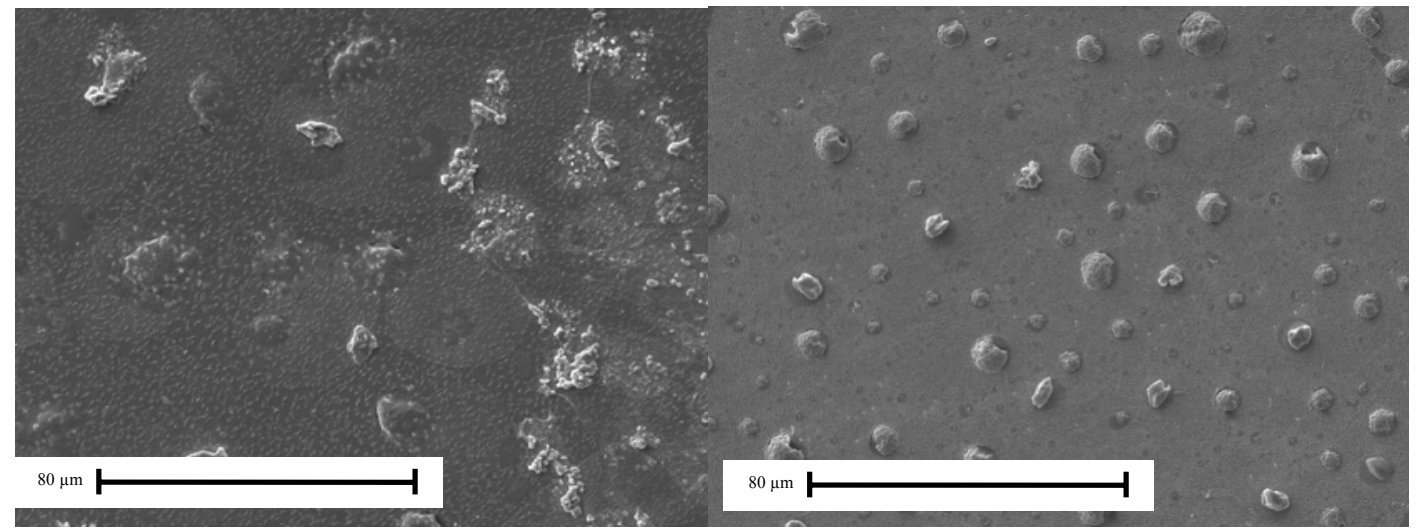

(a)

(b)

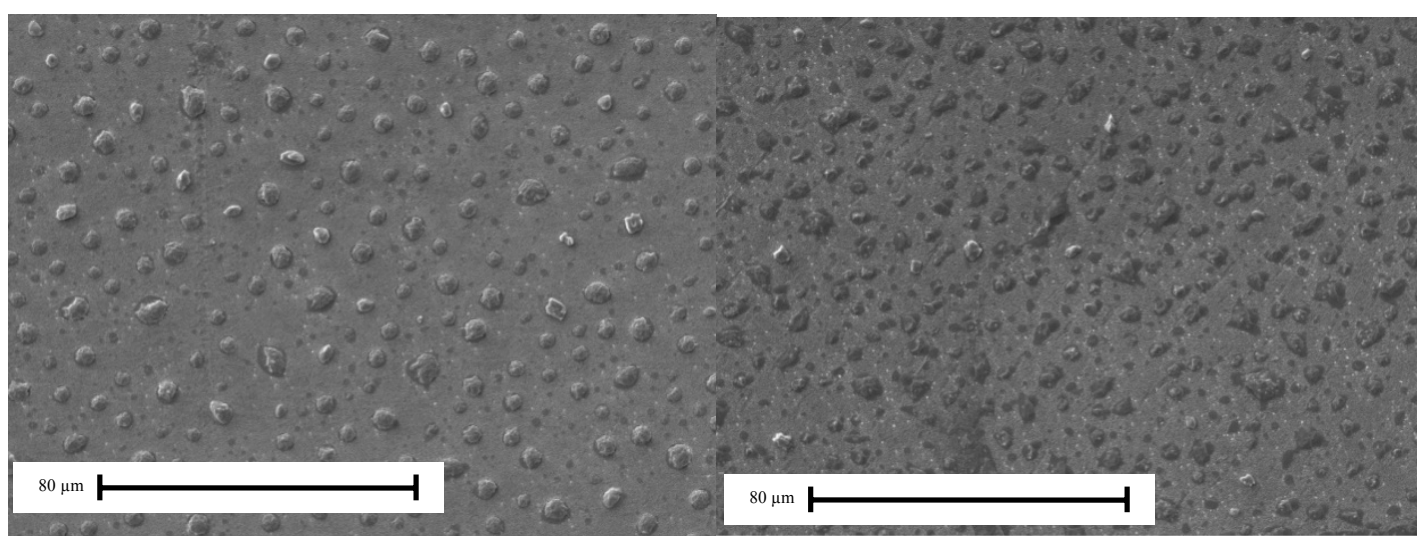

(c)

(d)

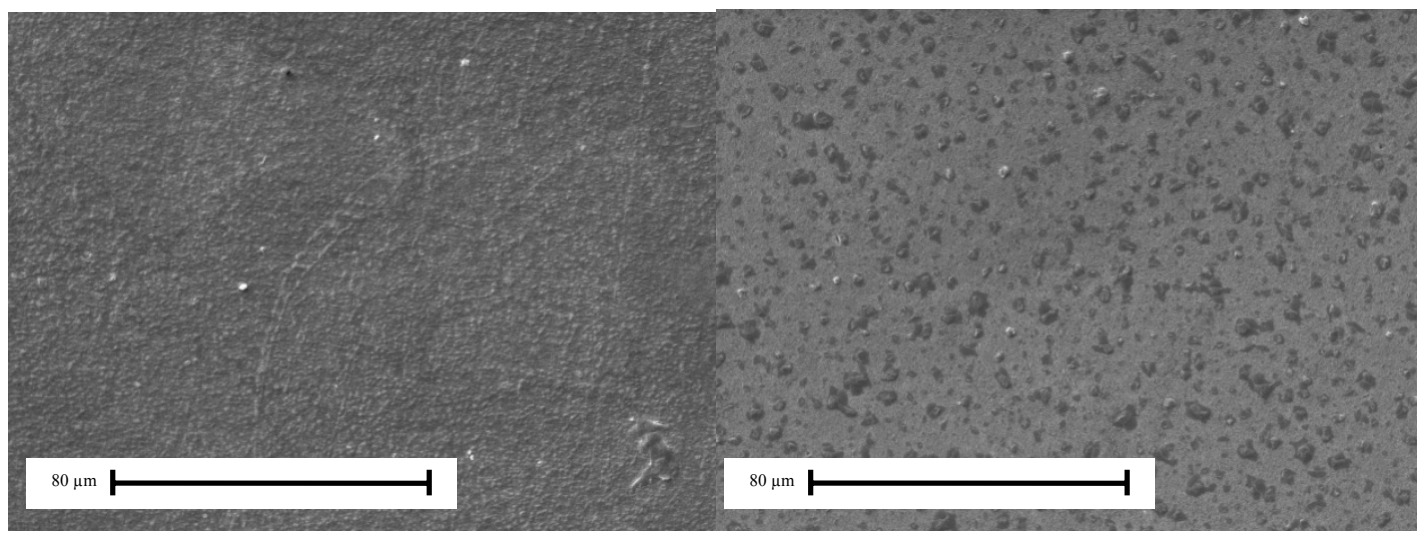

(e)

(f)

Figure 8 -SEM micrographs of the KrF excimer laser whole area irradiated samples (a) EWA100, (b) EWA150, (c) EWA200, (d) EWA250, (e) EWA250_500 and (f) EWA250_1000 after 24 hrs incubation . 


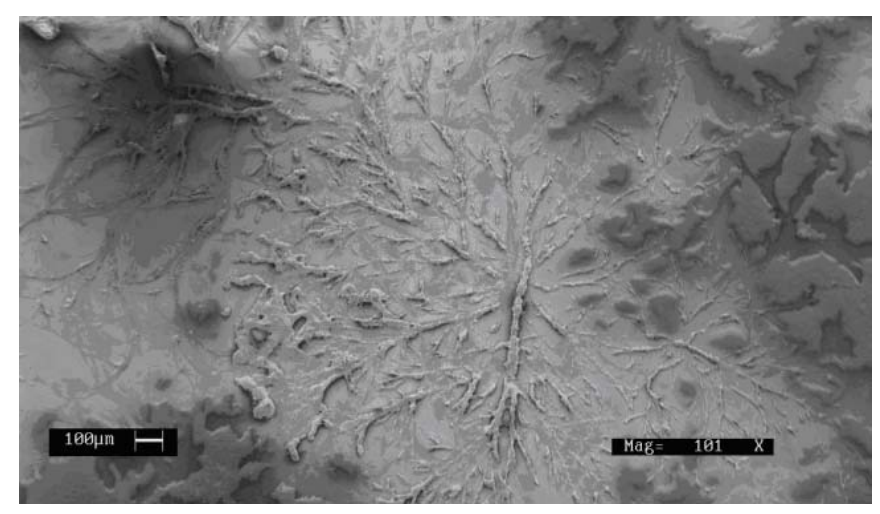

(a)

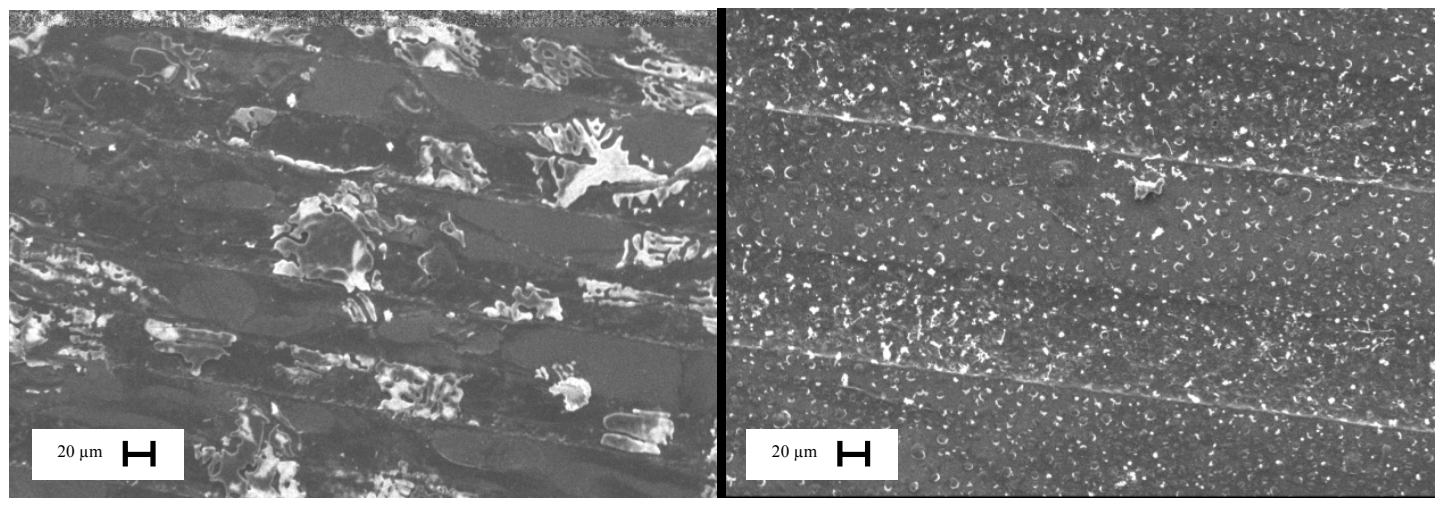

(b)

(c)

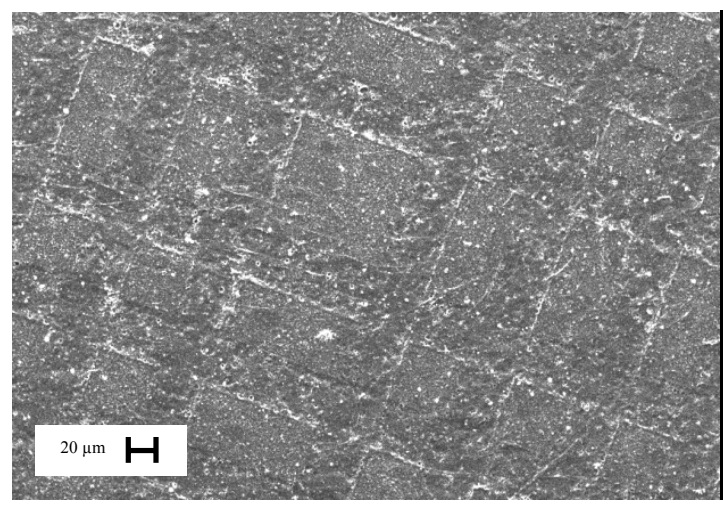

(d)

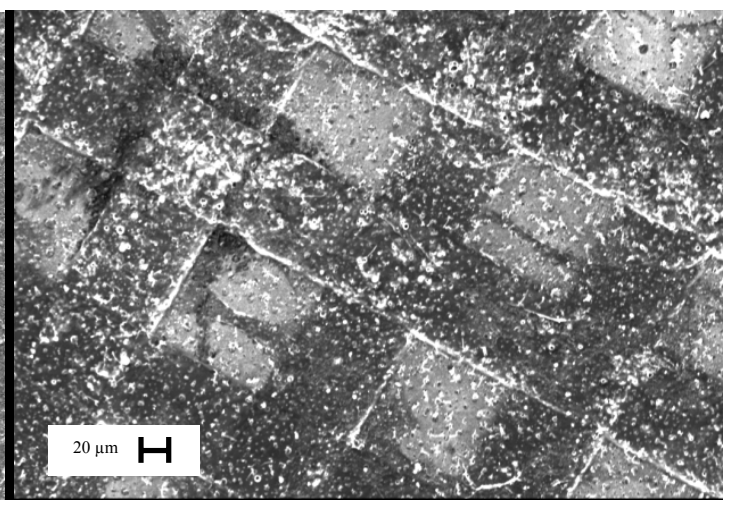

(e)

Figure 9 -SEM micrographs of a) the as-received sample and the KrF excimer laser-induced patterned samples (b) ET50, (c) ET100, (d) EH50 and (e) EH100 following four days incubation. 


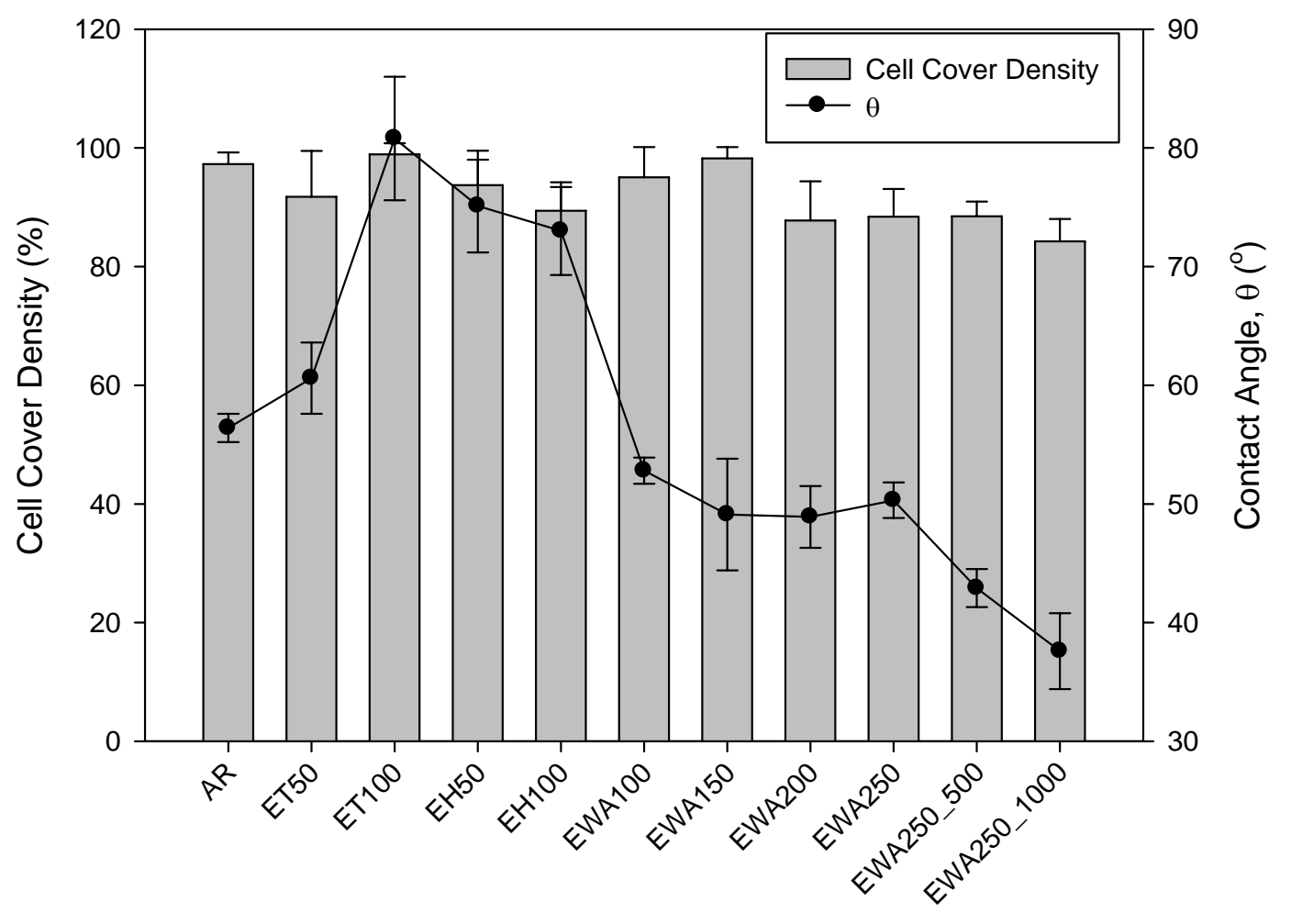

Sample I.D.

Figure 10 - Histogram showing the cell cover density in relation to $\theta$ for all KrF excimer laser processed samples following four days incubation.

(One-Way ANOVA showed that there was no over significance with $F=3.266$ and $p=0.010$. Scheffe's range test showed that there was no statistical difference between the samples on account of each result being too similar ${ }^{*} p<0.5$ ). 


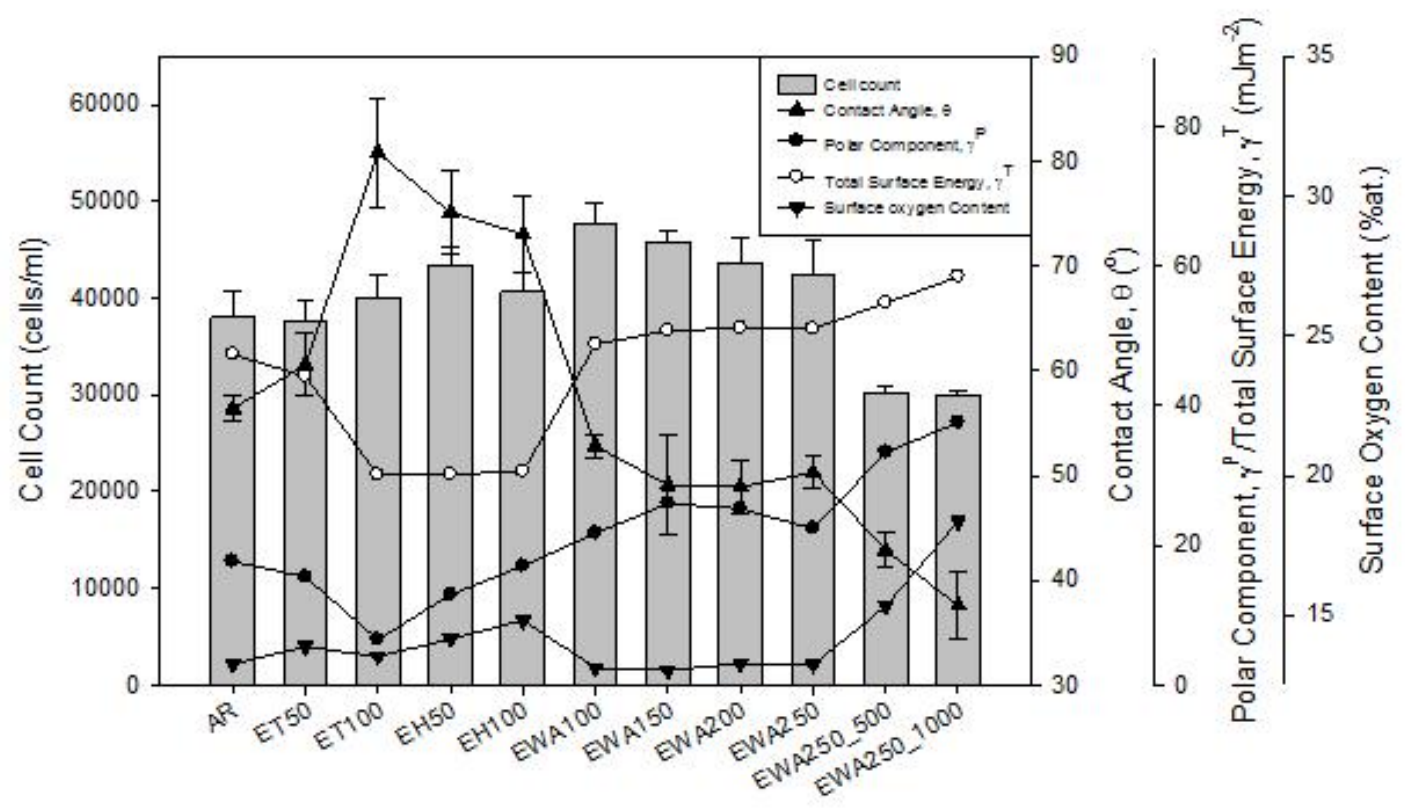

Sample I.D.

Figure $11-\left(\right.$ a) Histogram showing the cell count in relation to $\theta, \gamma^{P}, \gamma^{T}$ and surface oxygen content for all KrF excimer laser processed samples following four days incubation.

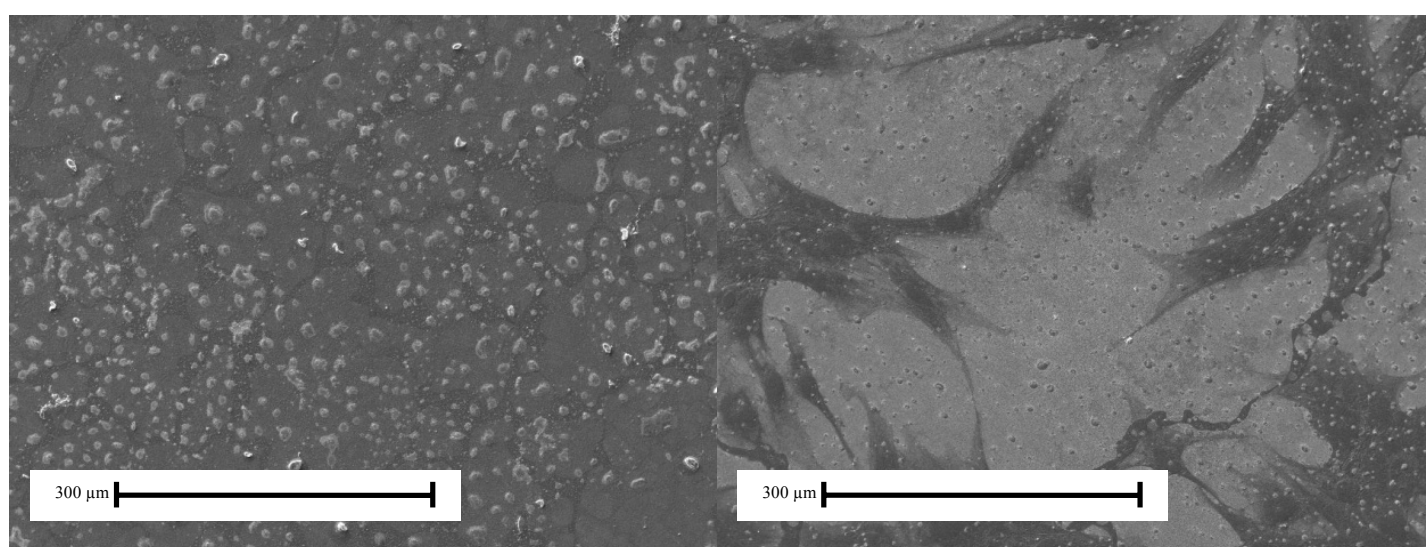


(a)

(b)

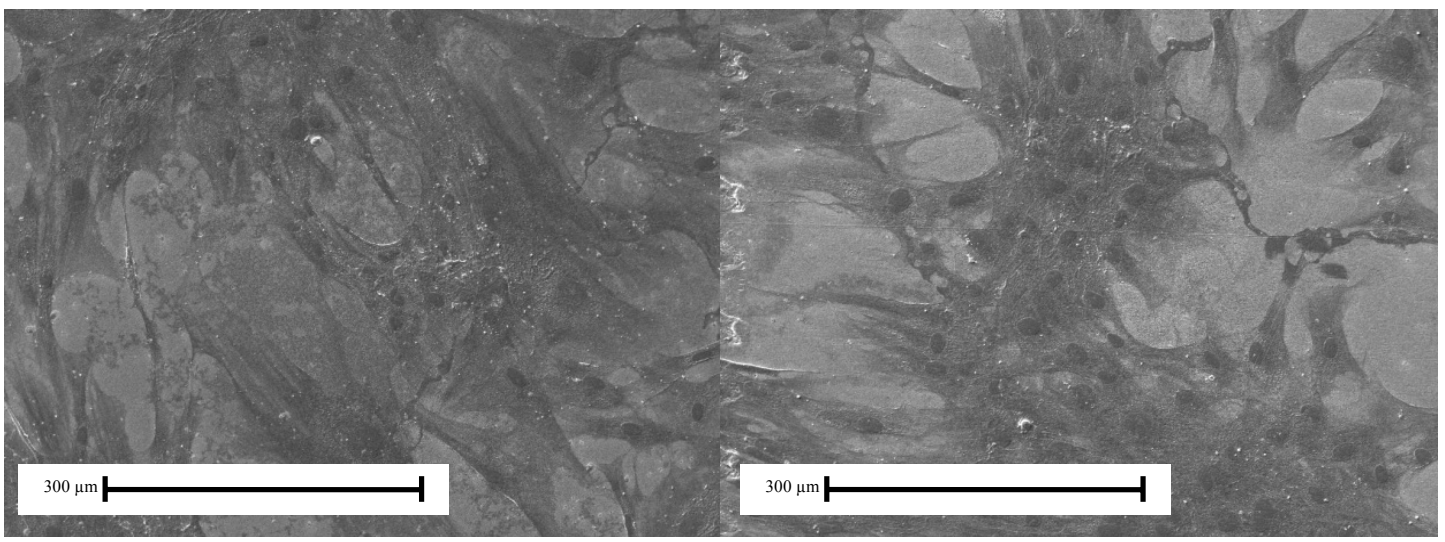

(c)

(d)

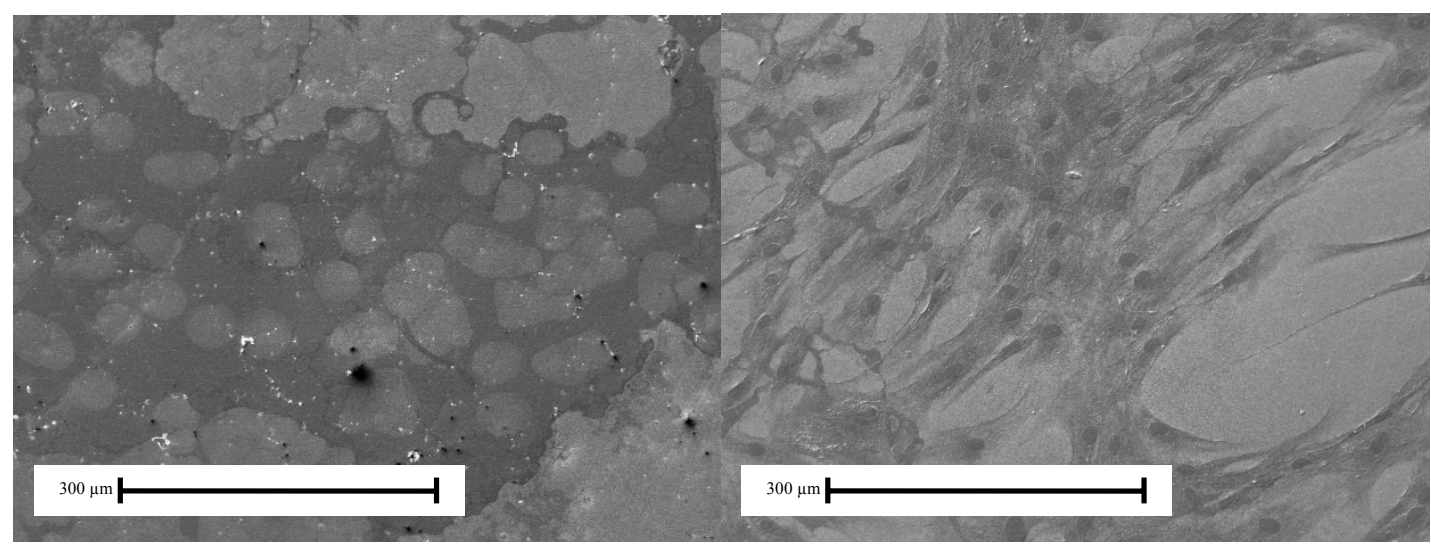

(e)

(f)

Figure 12 - SEM micrographs of KrF excimer laser whole area irradiative processed samples (a) EWA100, (b) EWA150, (c) EWA200, (d) EWA250, (e) EWA250_500 and (f) EWA250_1000 following four days incubation

Table 1 - Results summary for all samples showing roughness parameters, surface oxygen content and wettability characteristics for KrF processed nylon 6,6.

\begin{tabular}{|c|c|c|c|c|c|c|c|}
\hline Sample ID & $(\mu \mathrm{m})$ & $(\mu \mathrm{m})$ & $\begin{array}{c}\text { Polar } \\
\text { Component, } \\
\gamma^{\mathrm{P}} \\
\left(\mathrm{mJm}^{-2}\right)\end{array}$ & $\begin{array}{c}\text { Dispersive } \\
\text { Component, } \\
\gamma^{\mathrm{D}} \\
\left(\mathrm{mJm}^{-2}\right)\end{array}$ & $\begin{array}{c}\text { Total } \\
\text { Surface } \\
\text { Free } \\
\text { Energy, } \gamma^{\mathrm{T}} \\
\left(\mathrm{mJm}^{-2}\right)\end{array}$ & $\begin{array}{l}\text { Surface } \\
\text { Oxygen } \\
\text { Content }\end{array}$ & $\begin{array}{c}\text { Contact } \\
\text { Angle }\end{array}$ \\
\hline AR & 0.126 & 0.029 & 17.69 & 29.66 & 47.34 & 13.26 & $56.4 \pm 1.2$ \\
\hline \multicolumn{8}{|c|}{ Laser-Induced Patterned Samples } \\
\hline ET50 & 0.281 & 0.312 & 15.48 & 28.74 & 44.22 & 13.87 & $60.6 \pm 3.0$ \\
\hline ET100 & 1.320 & 0.679 & 6.52 & 23.54 & 30.06 & 13.53 & $80.8 \pm 5.2$ \\
\hline
\end{tabular}




$\begin{array}{crrrrrrr}\text { EH50 } & 0.739 & 0.548 & 12.94 & 17.24 & 30.17 & 14.15 & 75.1 \pm 3.9 \\ \text { EH100 } & 1.530 & 1.032 & 17.06 & 13.55 & 30.61 & 14.83 & 73.0 \pm 3.7\end{array}$

Whole Area Irradiative Processed Samples

\begin{tabular}{cccccccc} 
EWA100 & 0.119 & 0.029 & 21.72 & 27.08 & 48.79 & 13.11 & $52.8 \pm 1.1$ \\
EWA150 & 0.092 & 0.039 & 25.98 & 24.76 & 50.74 & 13.03 & $49.1 \pm 4.7$ \\
EWA200 & 0.108 & 0.030 & 25.26 & 25.86 & 51.12 & 13.28 & $48.9 \pm 2.6$ \\
EWA250 & 0.107 & 0.031 & 22.37 & 28.66 & 51.03 & 13.24 & $50.3 \pm 1.5$ \\
EWA250_500 & 0.164 & 0.039 & 33.31 & 21.40 & 54.71 & 15.32 & $42.9 \pm 1.6$ \\
EWA250_1000 & 0.198 & 0.036 & 37.56 & 20.89 & 58.46 & 18.36 & $37.6 \pm 3.2$ \\
\hline
\end{tabular}

